\title{
Cyclic and Fatigue Behaviour of Rock Materials: Review, Interpretation and Research Perspectives
}

\author{
B. Cerfontaine ${ }^{1} \cdot$ F. Collin ${ }^{1}$
}

Received: 3 March 2017 / Accepted: 26 September 2017

(c) Springer-Verlag GmbH Austria 2017

\begin{abstract}
The purpose of this paper is to provide a comprehensive state of the art of fatigue and cyclic loading of natural rock materials. Papers published in the literature are classified and listed in order to ease bibliographical review, to gather data (sometimes contradictory) on classical experimental results and to analyse the main interpretation concepts. Their advantages and limitations are discussed, and perspectives for further work are highlighted. The first section summarises and defines the different experimental set-ups (type of loading, type of experiment) already applied to cyclic/fatigue investigation of rock materials. The papers are then listed based on these different definitions. Typical results are highlighted in next section. Fatigue/cyclic loading mainly results in accumulation of plastic deformation and/or damage cycle after cycle. A sample cyclically loaded at constant amplitude finally leads to failure even if the peak load is lower than its monotonic strength. This subcritical crack is due to a diffuse microfracturing and decohesion of the rock structure. The third section reviews and comments the concepts used to interpret the results. The fatigue limit and $S-N$ curves are the most common concepts used to describe fatigue experiments. Results published from all papers are gathered into a single figure to highlight the tendency. Predicting the monotonic peak strength of a sample is found to be critical in order to compute accurate $S-N$ curves. Finally, open questions are listed to provide a state of the art of grey areas in the understanding of fatigue mechanisms and challenges for the future.
\end{abstract}

\footnotetext{
B. Cerfontaine

b.cerfontaine@ulg.ac.be

F. Collin

F.collin@ulg.ac.be

1 Allee de la Decouverte, 9, 4000 Liège, Belgium
}

Keywords Fatigue $\cdot$ Cyclic loading $\cdot$ Review $\cdot$ Natural Rock $\cdot$ Fatigue strength

\section{Introduction}

Environmental and human-induced loading acting on manmade works is cyclic in essence. From the wind and wave effects to earthquake- and traffic-induced wave propagation, structures designed by engineers are subjected to repeated time-dependent loads. This definition covers a large range of loadings distinct in amplitude and frequency.

Early studies on cyclic rock behaviour are devoted to mining sciences (Burdine 1963; Haimson and Kim 1971). Researchers seek to master the environmental variables to exploit material, through blasting and drilling processes. Investigations on this topic are still ongoing to improve rock-cutting (Ghamgosar et al. 2017) or hydraulic fracturing (Zang et al. 2013) technologies. Further research works are devoted to protect against environmental threats: designing tunnels against earthquakes (Hashash et al. 2001), forecasting volcanic hazard (Kendrick et al. 2013; Heimisson et al. 2015), assessing the freeze-thaw cycles on tunnels built in hostile cold regions (Zhang et al. 2004; Liu et al. 2015), studying the ageing of pillars due to variations of water table level (Sorgi and De Gennaro 2011) or estimating the long-term stability of old monuments (Cattaneo and Labuz 2001; Jamshidi et al. 2013) or buildings (Hale and Shakoor 2003) against weathering. Oil and gas storage, mainly in salt mines, is another application where cyclic loading is imposed to the environment by human activities by successive emptying and filling (Cosenza et al. 1999; Wang et al. 2015; Voznesenskii et al. 2017). The use of old mines as lower reservoirs for pumped storage hydroelectricity also generates cyclic 
loading/unloading of the environment (Steffen 2012; Pujades et al. 2016).

All of these applications highlight the need of a better understanding of the rock behaviour upon cyclic and especially fatigue loading in order to ensure the long-term reliability of the built structures. This paper focuses on the rock behaviour, excluding plain concrete for which a review upon fatigue may be found in Lee and Barr (2004). A general review on fatigue behaviour of materials can be consulted in Schijve (2003). The main objective and originality of this paper are to provide a comprehensive state of the art of fatigue and cyclic loading of natural rock materials. It aims at classifying and organising results and interpretations, sometimes contradictory, published in the literature over the last 50 years. It provides a global picture of the published papers, classical results and available data for researchers developing constitutive laws, since information often widespread in many different papers is summarised here. It is also dedicated to practitioners who can find a summary of fatigue strength results and select papers related to a particular material. Finally, different concepts related to the interpretation of fatigue results are commented and analysed, pointing out their advantages and limitations. Shadow zones and open questions are highlighted in order to be an incentive for new research works and projects.

This work is decomposed into three main sections. The first one classifies different experimental set-ups classically published in the literature. The second part describes typical results observed or measured during fatigue experiments. They are illustrated by several examples rather than simply listed. If possible, monotonic and cyclic results are compared to highlight their differences. Finally, concepts used to synthesise results are reviewed and their limitations pointed out. These limitations are starting points of future research work. Finally, a list of all documents related to cyclic mechanical loading used to elaborate this paper is provided in "Appendix".

\section{Experimental Set-up}

References to cyclic loading of rock materials in the literature cover many different experimental conditions. Subsequently, physical phenomena investigated as well as results may strongly differ. In addition, some concepts are frequently used as synonym (cyclic/dynamic) or (static/monotonic) while they are not, introducing some confusion. This section firstly describes all concepts that will be used to list and classify references from the literature.

\subsection{Loading}

The loading of a rock sample may be considered dynamic if the inertial forces generated within the material are significant with respect to the loading force. On the contrary, the inertial forces are negligible during quasi-static loading. Dynamic loading is commonly encountered due to shocks, blasting, high-speed trains, etc. If the loading rate is very high during experiment, waves are propagated and their superposition produces a stress distribution different from the quasi-static situation (Kumar 1968; Zhang et al. 2000; Cho et al. 2003; Zhu and Tang 2006). However, no universal loading rate threshold has been established to differentiate between quasi-static and dynamic behaviours of the material. A loading rate equal to $0.05 \mathrm{MPa} / \mathrm{s}$ for uniaxial compression experiment on granite is proposed in Zhao (2000). A threshold of deformation rate equal around $0.1-1 \mathrm{~s}^{-1}$ is proposed in Cho et al. (2003) for a Hopkinson bar test on granite.

Cyclic loading is characterised by an imposed timedependent load or displacement signal which exhibits a repeated pattern, by opposition to monotonic loading where applied load/deformation is continuously increasing/ decreasing. The cyclic load signal is the superposition of a mean load $\sigma_{\text {mean }}(t)$ and a cyclic amplitude $\Delta \sigma(t, T)$, where $T$ is the period of the load signal. Cyclic experiments are termed low cycle or high cycle depending on the number of cycles applied before failure occurs (Lee and Barr 2004). Once again there is no clear threshold, but low cycle ranges between tens to hundreds while high cycle ranges from thousands to millions. Period/frequency of the load signal is important since high frequencies mainly involve a dynamic loading.

The cyclic variation $\Delta \sigma(t, T)$ may have different shape over a period as represented in Fig. 1a. The most common cyclic stress variations are: square, linear or sinusoidal. A sinusoidal signal may be more representative of stress wave generated during rock burst or earthquakes, but linear variations are often simpler to apply (Bagde and Petroš 2005b). Although the maximum stress and period are identical for all signals, the energy provided to the sample as well as the imposed accelerations differs. It is proven on different materials that the shape of the signal affects the results (Gong and Smith 2003; Bagde and Petroš 2005b; Erarslan et al. 2014). Square signal is the most damaging, while linear variations are the least damaging.

Mean and cyclic stress amplitudes may be either constant or variable. Most of the tests found in the literature consider constant amplitude or increasing step by step as shown in Fig. 1b. High-cycle constant amplitude tests are mostly used to determine the fatigue limit of rock materials (Haimson and Kim 1971; Le et al. 2014), defined hereafter in Sect. 4.2. Subsequently, they are named fatigue tests. 


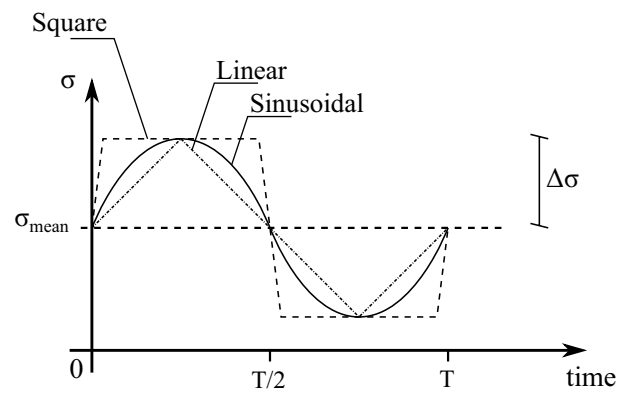

(a)

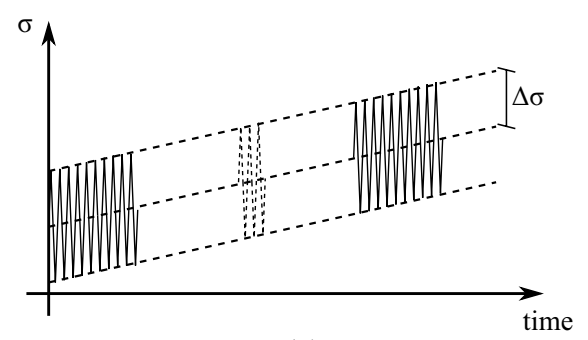

(c)

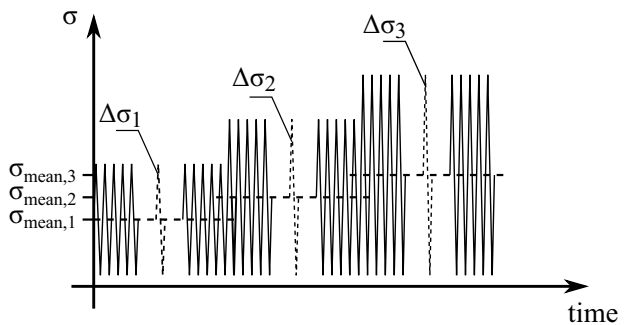

(b)

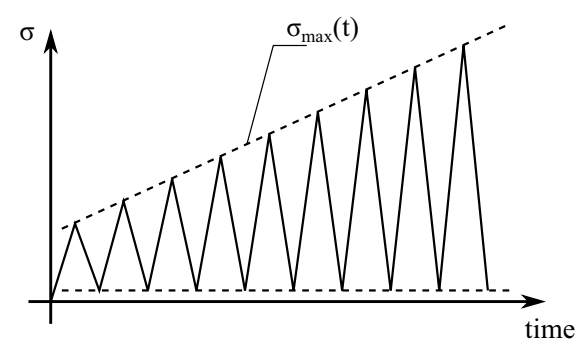

(d)

Fig. 1 a Different types of signal, $\mathbf{b}$ batch of constant amplitude signals, $\mathbf{c}$ ramp signal, $\mathbf{d}$ damage-controlled signal

Some variants may be considered where intervals at constant load are applied between two cycles (Fan et al. 2016, 2017). Figure 1d represents a damage-controlled test using increasing mean and amplitude stress (Tien et al. 1990; Martin and Chandler 1994; Eberhardt et al. 1999). In these studies, such kind of low-cycle test is used to correlate damage with variations in cohesion and mobilised friction. Some other authors investigate the evolution of the Young modulus and Poisson's ratio as representative of damage (Heap et al. 2010; Trippetta et al. 2013; Schaefer et al. 2015; Yang et al. 2015) or assess the stress history or a rock sample (Lavrov 2001). Finally, ramp signals are defined by a constant amplitude but an increasing mean stress, as represented in Fig. 1c.

\subsection{Type of Experiment}

Most of the experimental works report uniaxial (simple compression) tests (Attewell and Sandford 1974; Eberhardt et al. 1999; Bagde and Petroš 2005a). Such tests are representative of stress state in mine pillars and around galleries. They are used in different design methods, especially for pillar stability (Martin and Maybee 2000; Bertuzzi et al. 2016). In addition, they are cheap and simple to carry out. Triaxial cyclic experiments at different confinements are attracting more attention (Gatelier et al. 2002; Liu and He 2012; Wang et al. 2013; Ma et al. 2013; Yang et al. 2015) since samples exhibit different behaviour with increasing confinement. In addition, they are necessary to calibrate advanced constitutive laws. Indirect tensile tests are also carried out to investigate more deeply the fundamental fatigue fracture process or estimate the tensile strength of a material (Erarslan and Williams 2012b; Erarslan et al. 2014; Ghamgosar and Erarslan 2016; Wang et al. 2016; Erarslan 2016).

Three-point and four-point flexion tests are much less common and also provide information on the tensile strength (Cattaneo and Labuz 2001; Cardani and Meda 2004). They are often applied to the studying of natural stone or old buildings stability. Another type of bending test is proposed in Jamali Zavareh et al. (2017) where alternate compression and traction are generated in a clamped sample. Thermal or freeze-thaw cycles are commonly encountered to study rock weathering (Zhang et al. 2004; Martinez-Martinez et al. 2013; Liu et al. 2015). Despite quite different from mechanical loading, degradation processes may be common to both types of experiments. Cycles of wetting and drying may also be considered but are rare (Hale and Shakoor 2003).

\section{Typical Results}

In the previous section, we provide a broad definition of the cyclic behaviour of rock materials. Documents related to the mechanical cyclic behaviour are listed in "Appendix" and classified with respect to the previous criteria. In this section, we analyse typical measures and observations obtained during high-cycle constant load or low-cycle damage-controlled tests. We neglect weathering or freeze-thaw tests and focus on the mechanical behaviour. 


\subsection{Stress-Strain Curves}

Time evolution of applied load and displacement is primary results of the experiments. They are summarised as stress-strain evolution. Two examples are provided for uniaxial (Royer-Carfagni and Salvatore 2000) and triaxial (Liu and $\mathrm{He} 2012$ ) conditions in Figs. 2 and 3. These figures are representative of almost of all experiments where constant cyclic amplitudes are applied. The main observations are summarised below.

1. Failure is reached for a maximum cyclic stress lower than the estimated monotonic strength of the intact rock. In the first example, 45 cycles at constant amplitude are necessary and 629 in the second example. This suggests that repeated cycles weaken the material's strength. Such a degradation is also observed in ramp signals for indirect tensile test (Erarslan and Williams 2012b; Erarslan et al. 2014).

2. Residual deformations are accumulated cycle after cycle, while the maximum stress applied is constant.

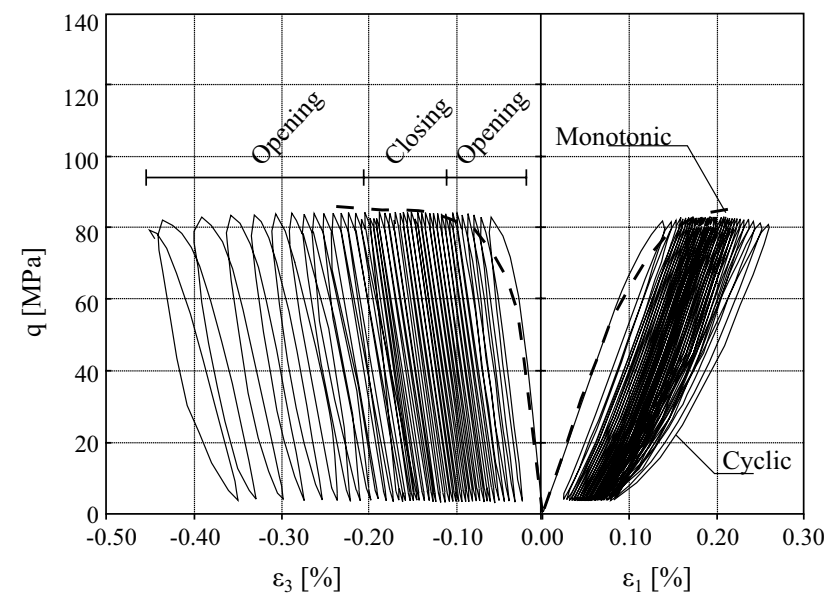

Fig. 2 Uniaxial test results on Lorano Marble at constant cyclic amplitude $(f=0.017 \mathrm{~Hz})$, failure after 45 cycles, from Royer-Carfagni and Salvatore (2000)

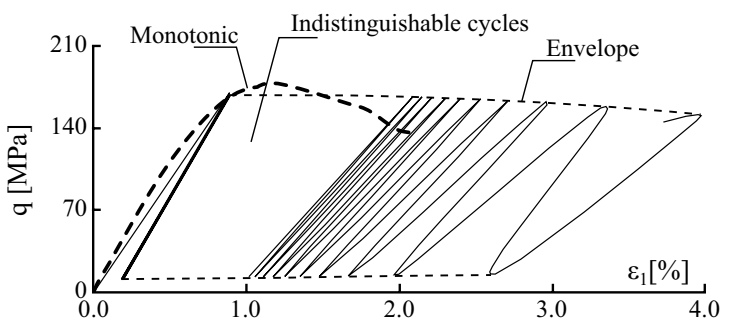

(a)
3. The rate of deformation accumulation is not constant all along the experiment. The first and last cycles exhibit more deformation accumulation than in between. However, accumulation rate decreases at the beginning and accelerates at the end, generating large hysteresis. Between these two stages, cycle's shape is mostly straight and close.

4. Lateral deformation is larger than the vertical one. Volumetric behaviour of the rock sample is compressive during first cycles but is mainly dilative otherwise, especially at low confinement. This is indeed related to the crack evolution and is discussed in Sect. 4.

5. The evolution of the secant/elastic modulus is not clear. Upon constant amplitude cyclic loading, most of the cycles appear to be parallel. No degradation is observed in Haimson and Kim (1971), Royer-Carfagni and Salvatore (2000), Cattaneo and Labuz (2001), Xiao et al. (2009, 2010), Fuenkajorn and Phueakphum (2010), Wang et al. (2013, 2015) and Ma et al. (2013), as reported in Fig. 2. Only a limited decrease is detected in Attewell and Farmer (1973), Liu and He (2012), Guo et al. (2012) and Le et al. (2014), see for instance in Fig. 3.

Several studies point out that monotonic stress-strain curves act as a failure locus for cyclically loaded samples (Haimson and Kim 1971; Martin and Chandler 1994; Yamashita et al. 1999; Zhang et al. 2008; Xiao et al. 2009; Guo et al. 2012; Song et al. 2013; Liu et al. 2017). An example of such a phenomenon is reproduced in Fig. 4 for a plaster specimen (Brown and Hudson 1974). The main advantage of such artificial material is to reduce inhomogeneity, anisotropy and dispersion of results.

Cyclic results (solid line) and the post-peak part of the monotonic load (dashed line) are represented together. The instability encountered during the cyclic loading corresponds to the failure locus obtained from monotonic displacement-controlled results. This excellent correspondence is not always observed for natural materials as shown in Fig. 3. However, this may be primary due to the dispersion

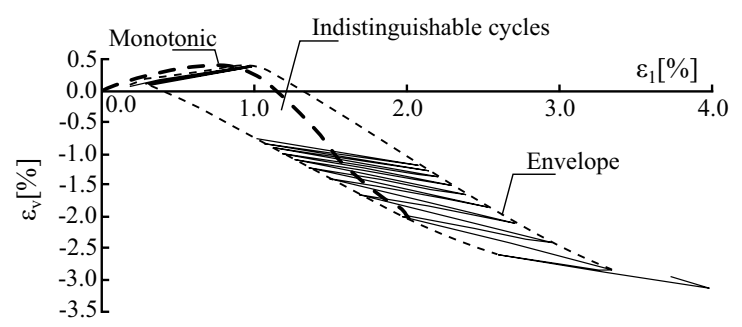

(b)

Fig. 3 Triaxial test results (confining pressure 30MPa) at constant amplitude on sandstone specimens (20-320 kN, $f=1 \mathrm{~Hz}$ ), failure after 629 cycles, from Liu and $\mathrm{He}$ (2012) 


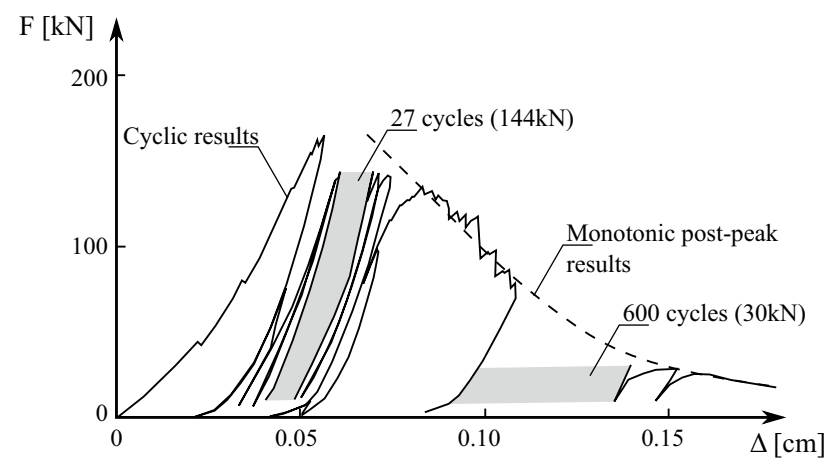

Fig. 4 Uniaxial stress-strain relation for gypsum plaster reconstituted specimen, comparison between monotonic (dashed line) and cyclic relations (Brown and Hudson 1974)

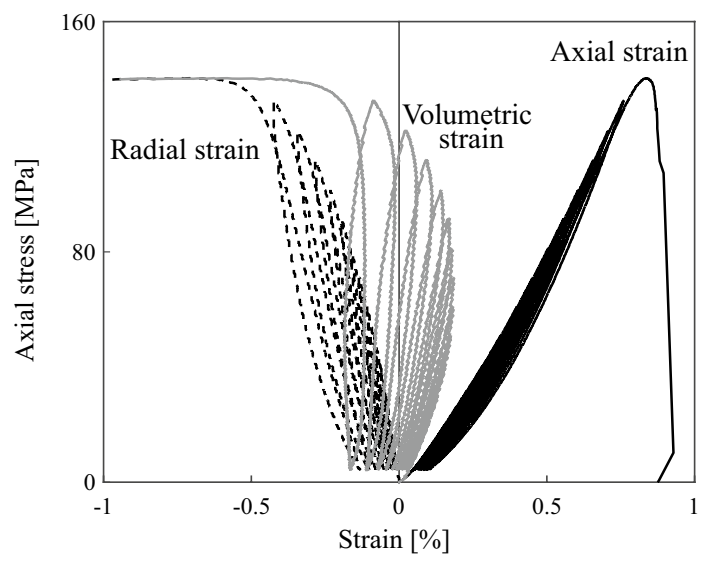

Fig. 5 Representative stress-strain curve for damage-controlled test on Etna Basalt, from Heap et al. $(2009,2010)$

of rock sample strengths, producing very different results. Interestingly, such relation is also observed for cyclically loaded sands (Alarcon-Guzman et al. 1989) or creep as reported later (Brantut et al. 2014).

Damage-controlled tests, involving increasing maximum stress, should be considered apart. The number of cycles applied is mostly low and varies between 5 and 50 (Eberhardt et al. 1999; Heap et al. 2010; Trippetta et al. 2013; Schaefer et al. 2015; Yang et al. 2015). The increasing stress from one cycle to the other approaches a monotonic loading, although some differences are noted, especially a slight decrease in strength (Yang et al. 2015). Figures 5, 6 and 7 from Heap et al. $(2009,2010)$ are representative of many damage-controlled tests, and the main observations are summarised below.

1. Failure is reached for a maximum stress applied close to the monotonic strength of the material (Eberhardt et al. 1999; Yang et al. 2015, 2017). Some authors report a lower strength after cycles of unloading/reloading (Ken-

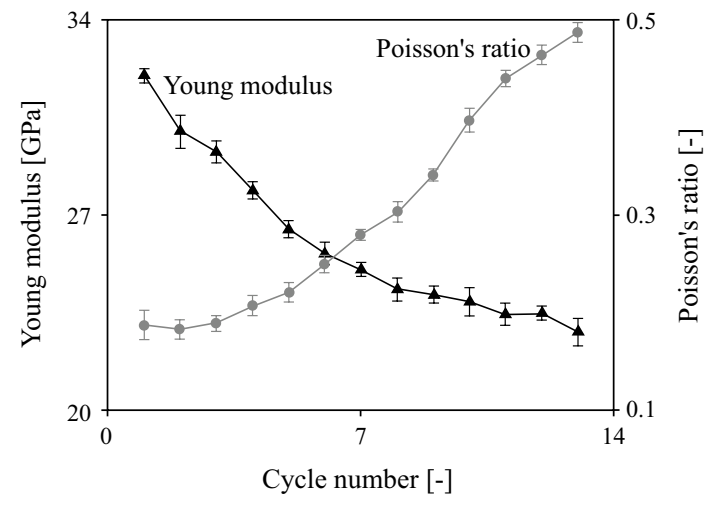

Fig. 6 Evolution of static elastic modulus and Poisson's ratio with increasing cycle number for damage-controlled test of Etna Basalt, from Heap et al. $(2009,2010)$

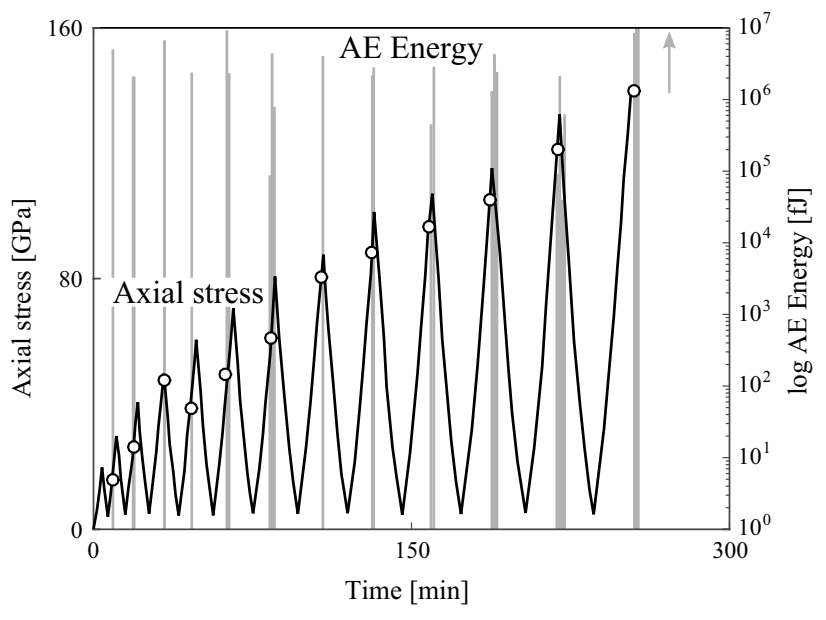

Fig. 7 Evolution of acoustic emission (AE) energy and axial stress evolution as a function of time, for damage-controlled test of Etna Basalt, from Heap et al. (2009, 2010). Solid circles indicate the points at which $\mathrm{AE}$ activity recommenced on each loading cycle

drick et al. 2013; Meng et al. 2016), while some others (Yang et al. 2015) present example of increasing strength. A particular case where a sample failed for a load lower than the previous applied maximum stress during the same test is even reported in Schaefer et al. (2015). The effect of these cycles on the final strength depends on the type of rock, the confining pressure and the number of cycles applied.

2. Strain accumulates slowly with the number of cycles before peak (Heap et al. 2010; Schaefer et al. 2015) but in a much lower amount than previously described for constant amplitude cycles. However, cycles show a hysteresis, increasing as the maximum stress applied rises up (Martin and Chandler 1994; Heap et al. 2010; Yang et al. 2015). 
3. The evolutions of the Young modulus and the Poisson's ratio are particularly investigated during damage-controlled tests. Contrary to constant amplitude tests, most of the tests describe a trend of decreasing Young modulus (up to one third of decrease) (Eberhardt et al. 1999; Heap et al. 2009, 2010; Kendrick et al. 2013), while some others report increasing Young modulus (Trippetta et al. 2013). The Young modulus is also reported as increasing for the first few cycles and decreasing afterwards (Yang et al. 2015). On the other hand, Poisson's ratio increases in all studies, sometimes strongly [up to 600\% (Heap et al. 2010)]. They mostly indicate a dilative behaviour of the material and crack propagation, discussed in the following section.

\subsection{Deformation Evolution}

It is difficult to compare the full response signal of different samples for a large number of cycles since the amount of data is very large. Therefore, it is common to analyse the evolution of a single value summarising results with respect to the number of cycles applied. For instance, the residual deformation/displacement (after unloading) is classically analysed as shown in Fig. 8, from Attewell and Farmer (1973). Evolution of stiffness (elastic properties or secant modulus) is sometimes provided for large number of cycles and exhibit a similar trend (Xiao et al. 2010; Guo et al. 2012). However, this variable must be post-processed introducing more uncertainties.

Results often present a three-stage behaviour (Tien et al. 1990; Royer-Carfagni and Salvatore 2000; Fuenkajorn and Phueakphum 2010; Xiao et al. 2010; Erarslan and Williams 2012b; Guo et al. 2012) similar to classic description of brittle creep (Cruden 1974; Brantut et al. 2013) and subcritical crack growth (Atkinson 1984). Stage I is referred as decelerating, indicating a stabilisation. Stage II is named stationary, and the accumulation rate is constant. It may be very short

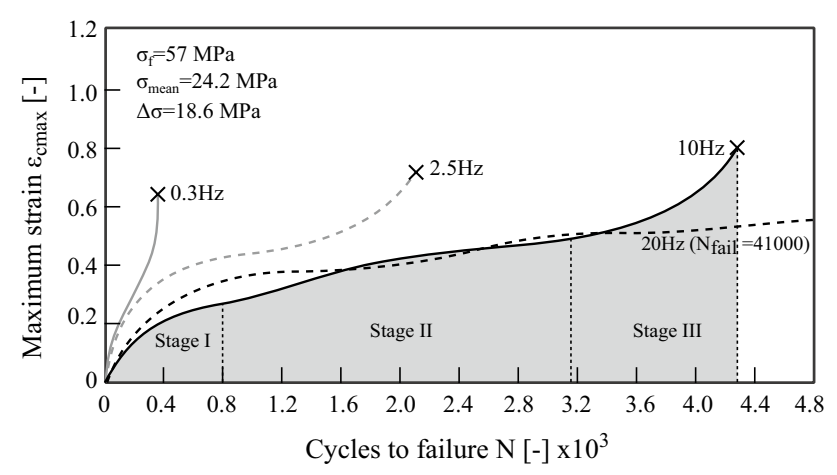

Fig. 8 Influence stress frequency upon failure strain, uniaxial test at constant amplitude, limestone, $\sigma_{f}=$ monotonic strength (Attewell and Farmer 1973) or may consist of the most part of the experiment as shown in Fig. 8. Stage III is termed accelerating, since the rate of degradation increases up to the final failure of the rock sample. These phases are directly correlated with open or close cycles in the stress-strain curves described in Sect. 3.1.

For damage-controlled stress, the Young modulus and Poisson's ratio evolutions are particularly investigated, as previously reported. It can be categorised in several stages similarly to the strain evolution (Yang et al. 2015). Stage I depicts an increase in Young modulus and a slight decrease in Poisson's ratio, corresponding to material hardening. The number of cycles of this phase obviously depends on the stress amplitude increments. Stage II corresponds to material degradation where the Young modulus decreases and Poisson's ratio increases slightly (Yang et al. 2015), or are almost constant (Trippetta et al. 2013). Finally, at failure (Stage III) Poisson's ratio increases sharply and Young modulus decreases.

Although comparisons are considerably facilitated by such summarised results, it is still difficult to identify a universal evolution law even for a given material. Indeed, these curves are strongly dependent on many parameters as reported in Table 1, modifying the number of cycles to failure and curve's shape. For instance, frequency of the cyclic loading considerably modifies the shape and number of cycles to failure as reported in Fig. 8. At constant maximum applied stress, the cyclic amplitude (or minimum stress) is also proven to modify the number of cycles to failure (Erarslan and Williams 2012b; Momeni et al. 2015).

\subsection{Dilatancy}

Dilatancy is often macroscopically measured by strain gauges or LVDTs, during the experiments and especially for unconfined uniaxial tests. It is inherently anisotropic and stress-induced (Sondergeld and Estey 1981; Scholz and Koczynski 1979) since the loading creates microcracks oriented in a direction parallel to the loading. Consequently, it is observed that macroscopic lateral deformation is larger than the longitudinal one (at low confining pressure), even for initially isotropic materials (Royer-Carfagni and Salvatore 2000; Liu and He 2012; Bastian et al. 2014). Larger volumetric deformation is observed during cyclic tests, since longitudinal and transversal deformation are larger.

The initial anisotropy of the rock fabric also influences the observed volumetric deformation. A study Gatelier et al. (2002) presents results of damage tests where cycles of constant amplitudes are applied up to the stabilisation of accumulated deformation. Volumetric irreversible strain reached at the end of each loading step is presented in Fig. 9. The rock material is orthotropic, and its plane of isotropy is inclined of an angle $\theta$ with respect to the horizontal direction. Two mechanisms are in competition 
Table 1 Influence of different factors on the number of cycles to failure or deformation for large number of cycles

\begin{tabular}{|c|c|c|}
\hline Factor & Influence & References \\
\hline Frequency & Increase number of cycles to failure & $\begin{array}{l}\text { Attewell and Farmer (1973), Tien et al. (1990), Fuen- } \\
\text { kajorn and Phueakphum (2010), Ma et al. (2013), } \\
\text { Momeni et al. (2015), Liu et al. (2017) }\end{array}$ \\
\hline Maximum stress and amplitude & Decrease number of cycles to failure & $\begin{array}{l}\text { Xiao et al. (2009, 2010), Fuenkajorn and Phueakphum } \\
\text { (2010), Erarslan and Williams (2012b), Erarslan } \\
\text { et al. (2014), Momeni et al. (2015) }\end{array}$ \\
\hline Confinement & $\begin{array}{l}\text { Increase final deformation, increase number of cycles } \\
\text { of accelerating phase }\end{array}$ & Burdine (1963), Tien et al. (1990), Liu and He (2012) \\
\hline Saturation degree & Decrease number of cycle to failure & Burdine (1963), Tien et al. (1990) \\
\hline Anisotropy & $\begin{array}{l}\text { Number of cycles and deformation depend on lithol- } \\
\text { ogy }\end{array}$ & $\begin{array}{l}\text { Royer-Carfagni and Salvatore (2000), Gatelier et al. } \\
\text { (2002) }\end{array}$ \\
\hline Waveform & $\begin{array}{l}\text { Square waveform is more damaging than sinusoidal } \\
\text { one, adding intervals between cycles decreases dura- } \\
\text { tion of the test }\end{array}$ & Bagde and Petroš (2005a), Fan et al. $(2016,2017)$ \\
\hline Size of the rock sample & Increase number of cycles to failure & Le et al. (2014) \\
\hline
\end{tabular}

(for triaxial tests): compaction and microcracking (Gatelier et al. 2002). The decreasing tendency of compaction rate and the clear dilatancy indicates that microfracturing starts early in the experiment and finally becomes dominant. In addition, the angle $\theta$ clearly modifies results, indicating that natural initial anisotropy should be taken into account while they are most generally neglected when results are presented (Gatelier et al. 2002; Royer-Carfagni and Salvatore 2000).

Dilatancy effects are reduced with increasing confinement when the importance of compaction mechanism (pore collapse) is increasing (Gatelier et al. 2002; Heap and Faulkner 2008). In addition, the confinement increases the normal stress acting on each crack, enlarging the maximum shear stress sustainable without slipping. Confinement also

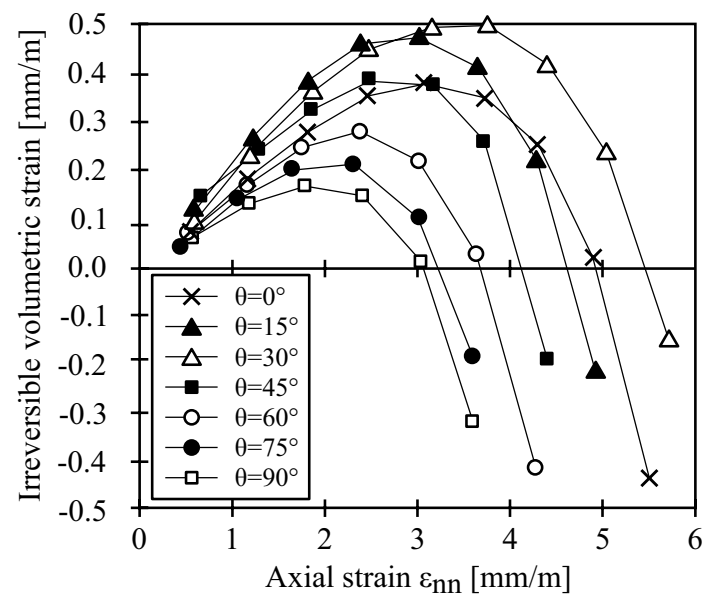

Fig. 9 Irreversible volumetric strain as a function of the axial strain $\epsilon_{n n}$ at the end of a loading step for different orientations of the strata, uniaxial test, sandstone (Gatelier et al. 2002) reduces the effect of initial anisotropy of the rock material (Bieniawski 1967; Attewell and Sandford 1974; Fredrich et al. 1989; Gatelier et al. 2002).

\subsection{Crack Development and Measurement}

Differences between monotonic and cyclic results for large number of cycles may be explained by distinct crack growth processes. Several studies on Brisbane tuff state that a lot of dust and fragments are created during indirect tensile cyclic loading (Erarslan and Williams 2012b; Erarslan et al. 2014; Erarslan 2016; Ghamgosar and Erarslan 2016; Ghamgosar et al. 2017), while a clear and clean crack is observed during monotonic tests. This comparison is reproduced in Fig. 10. Similar results are obtained for a sandstone material (Liu et al. 2017).

In addition, a wider fracture process zone is observed for cyclically loaded specimens as shown in Fig. 11. In this figure, consequences of the two ongoing mechanisms are clear. Cyclic loading induces a wider fracture process zone and branching of the crack, resulting in plastic deformation measured at macroscale (Le et al. 2014; Ghamgosar and Erarslan 2016; Erarslan 2016).

Many other studies report that decohesion of rock grains and matrix loosening is a consequence of the cyclic loading (Burdine 1963; Costin and Holcomb 1981; Martin and Chandler 1994; Widhalm et al. 1996; Eberhardt et al. 1999; Royer-Carfagni and Salvatore 2000; Zhao 2000; Zhang et al. 2000; Gatelier et al. 2002; Cardani and Meda 2004; Bagde and Petroš 2005a; Guo et al. 2012). This is coupled with a high density of microfracturing and a more diffuse damaging of the samples (Haimson and Kim 1971; Eberhardt et al. 1999; Cattaneo and Labuz 2001; Nejati and Ghazvinian 2014). 


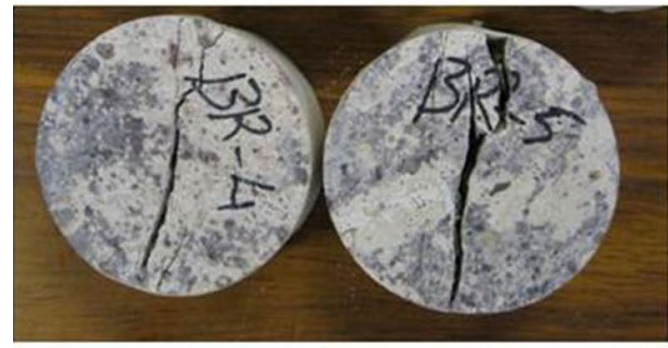

(a)

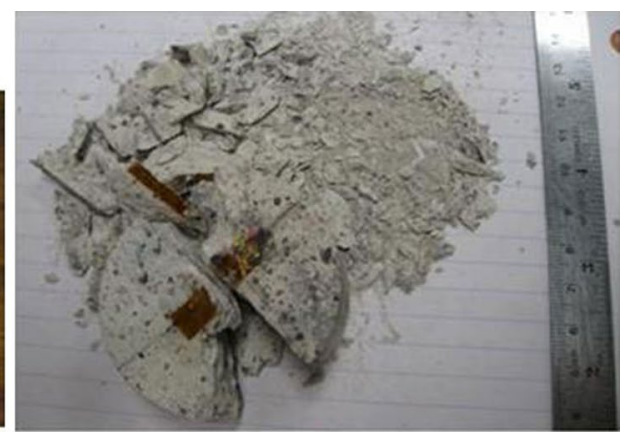

(b)

Fig. 10 Brazilian disc specimens of Brisbane tuff after failure, from Erarslan et al. (2014), a monotonic loading, b cyclic loading

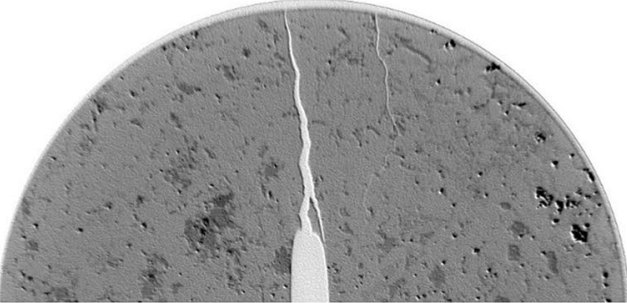

(a)

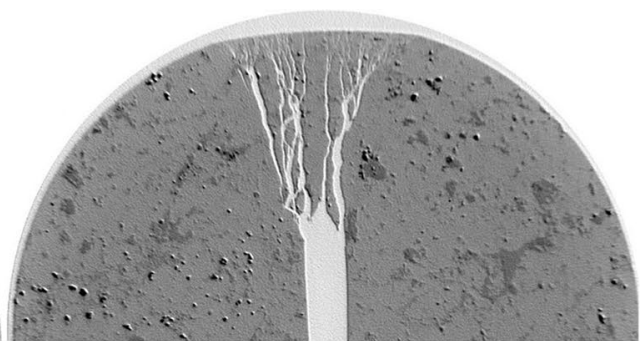

(b)

Fig. 11 Computed tomography of cracked chevron-notched Brazilian disc (CCNBD) on Brisbane tuff, from Ghamgosar and Erarslan (2016), a monotonic loading, b cyclic loading

For instance, a comparison on indirect tensile tests on Brisbane tuff is provided in Fig. 12. Scanning electron microscope observations are compared in both cases (Erarslan 2016). For monotonic loading, almost all grains on the failure surface are highly cracked and failure mode is brittle. For cyclically loaded specimens, most grains are cracked-free and failure holds along their boundaries. The primary fatigue mechanism is identified as inter-granular cracks (Erarslan 2016; Erarslan and Williams 2012a). A secondary mechanism results in wear and shearing between rock grains starting at contact points. This leads to intragranular cracks. Finally, failure results from the coalescence of many microcracks rather than the growth of a single macrocrack (Erarslan 2016).

Similar observations are reported for triaxial cyclic experiments $\left(\sigma_{3}=5 \mathrm{MPa}\right)$ and damage-controlled tests where a low number of cycles are applied (Yang et al. 2015). The authors carry out X-ray microcomputed tomography and observe that the crack pattern is much more complicated for cyclic than monotonic loading. They report axial and lateral tensile cracks in addition to the typical simple shear fracture. This implies that under certain conditions, a cyclic mechanism may be involved in the failure process even for a low number of cycles.
Acoustic emissions (AE) are defined as transient elastic waves generated by the rapid release of energy within a material (Lockner et al. 1992; Lavrov 2003; Antonaci et al. 2012). They result from the generation, propagation of (micro-), nucleation or coalescence of cracks (Kendrick et al. 2013). Therefore, their monitoring is a natural way to study the damage evolution during loading of rock or geomaterial specimens since this is a non-destructive procedure.

$\mathrm{AE}$ monitoring may be used to determine the position or energy released by cracks. Generally, the amplitude of the wave is correlated with the size of the fracture and they are correlated with the damage state of a rock specimen (Erarslan et al. 2014). Microscale fractures emit a large number of acoustic signal with a low amplitude, while macrocracks are characterised by few events of large amplitude. On the contrary, pore compaction is not expected to generate $\mathrm{AE}$ and friction between rough contact only induces lowamplitude AE (Trippetta et al. 2013). Prikryl et al. (2003) study the relations between acoustic emissions and the rock fabric. They identify that AE energy is strongly dependent on the grain size distribution of the material. They report that larger grains break at higher stress and release more energy than smaller ones. They also describe the influence of anisotropy on the fracture pattern, where secondary shearing 

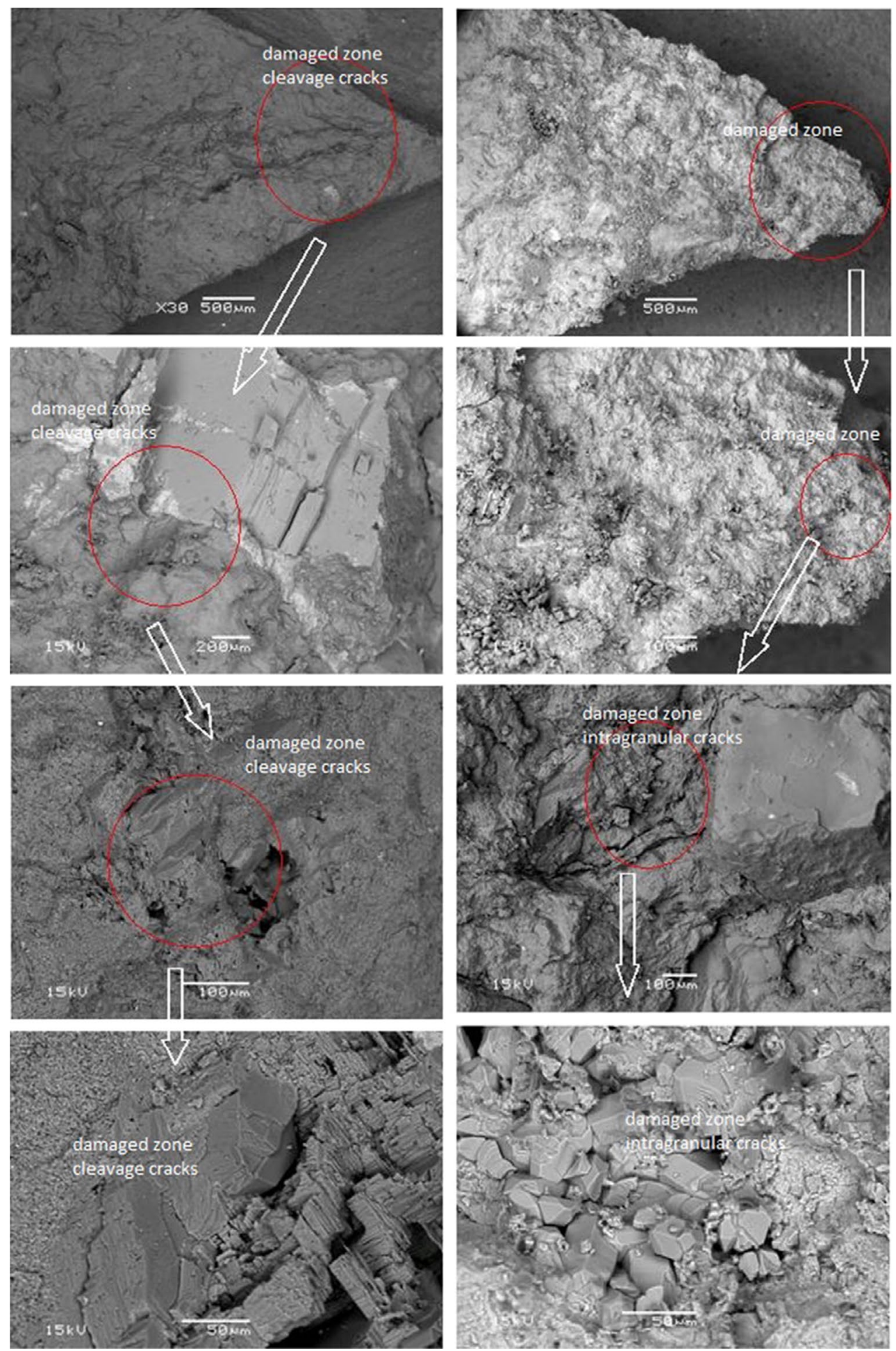

Fig. 12 Damage in the cement of a Brisbane tuff during indirect tensile test: (left, static loading) intra-granular cracks along grain and cleavage cracks on the failure surfaces (right, cyclic) grain decohe- sion, loosened grains and typical inter-granular cracks around grains on the failure surfaces, from Erarslan (2016) 
mode fractures are observed in addition of tensile crack during uniaxial loading.

$\mathrm{AE}$ are rarely monitored for cyclic tests with a large number of constant amplitude cycles (Jiang et al. 2009; Xiao et al. 2010; Karakus et al. 2016). Jiang et al. (2009) report that $\mathrm{AE}$ are well correlated with the stress-strain evolution. There are more hits at the beginning (first cycle). Then the number of hits per second is almost constant in the following cycles and increases when the specimen is close to failure.

Monitoring of AE is much more common for damagecontrolled tests (Lavrov 2001; Heap et al. 2009, 2010; Kendrick et al. 2013; Trippetta et al. 2013). It is mostly reported that the $\mathrm{AE}$ are not continuous during experiments, as previously presented in Fig. 7. During the first cycles, AE are measured almost from the beginning of the test and stop or decrease sharply during unloading. However, after the first cycle, AE start again when the previous maximum applied stress is overcome. This is the so-called Kaiser effect, further discussed in Sect. 4.5.

It should be mentioned that some other non-destructive techniques exist to monitor the fracture evolution of rock samples. Measurement of wave velocity is one of the most common (Rao and Ramana 1992; Lockner 1993; Meglis et al. 1995; Brantut et al. 2014; Voznesenskii et al. 2017). Microscopic thin sections are also often provided (Ghamgosar and Erarslan 2016; Wang et al. 2017). Tomography techniques are used in Chow et al. (1995) to assess the damage evolution of a rock sample. An interferometric process is used in Cattaneo and Labuz (2001) to study the damage propagation during cyclic three-point bending test. It is shown in this study that cyclic loading produces a more diffuse damage than monotonic one. Ákesson et al. (2004) study the influence of fabric and mineralogy on the microstructure. Digital image correlation is another means to measure the crack formation during loading (Song et al. 2016; Munoz and Taheri 2017).

This paragraph does not pretend to be exhaustive on monitoring methods or references associated. However, many previous studies demonstrate that the rock behaviour is strongly dependant on microcracking (Kranz 1983). Therefore, measurement and monitoring of crack have become necessary in the interpretation of results. All the presented methodologies, alone or combined, may be adopted to increase the understanding and interpretation of cyclic loading and its particular failure mechanisms.

\subsection{Partial Summary}

The objective of this section is to provide a global picture of experimental observations related to the cyclic and fatigue behaviours of rock materials, from macroscopic to microscopic effects. This particular type of loading may result in permanent vertical and lateral deformation as well as damaging of elastic properties. Dilatancy is most of the time observed as a consequence of the crack opening, especially at low confinement. It is also shown that a specific fracture process stems from this type loading and differs from monotonic loading. It generally leads to loosening and decohesion of the rock grains. Many different experimental conditions (confinement, rate of loading, anisotropy, saturation, etc.) influence the observations. Due to the relative complexity of the behaviour and heterogeneity of the material, theoretical concepts and key values must be defined to exploit results and compare rock materials or samples.

\section{Interpretations}

Typical results described before are difficult to use in practice since they contain a large amount of information (full load-displacement signal for instance). Their interpretation requires conceptual models able to explain all physical phenomena underlying experimental observations. Furthermore, strength parameters must be derived from experiments in order to design earthworks against fatigue issues. There is a need to formulate a fatigue indicator reproducing the evolution of the degradation process and predicting the safety margin against failure. This is also a first step towards the definition of more complex constitutive laws.

This section describes common interpretation concepts and gathers information from all papers devoted to the fatigue behaviour of rock materials. Their advantages but also their limitations are described here. The main objective of this section is to highlight shadow zones requiring more investigation. The close fatigue and creep behaviours are especially not well distinguished. The so-called Kaiser effect is also discussed. Finally, a flowchart relating the interpretation concepts with experimental set-ups is provided in order to help researchers/practitioners to design experimental campaign.

\subsection{Fatigue Mechanisms}

A simple frictional model is proposed in Scholz and Kranz (1974) and Zoback and Byerlee (1975) to explain the hysteresis loops observed in the stress-strain relation, for axial, lateral and volumetric deformations. This model is detailed in Fig. 13 for two kinds of axially oriented cracks. Between points $\mathrm{A}$ and $\mathrm{B}$, the solid behaves elastically. At point $\mathrm{B}$, the cracks open and slip up to the maximum stress $\mathrm{C}$, generating dilatancy. The unloading is elastic again until the maximum shear stress is mobilised within the crack (point D). Between $\mathrm{D}$ and $\mathrm{E}$, the crack slips in the reverse sense. The crack is closing but does not necessarily recover its initial position.

The irreversible accumulated volumetric deformation over a cycle is due to the cracks that do not close completely 

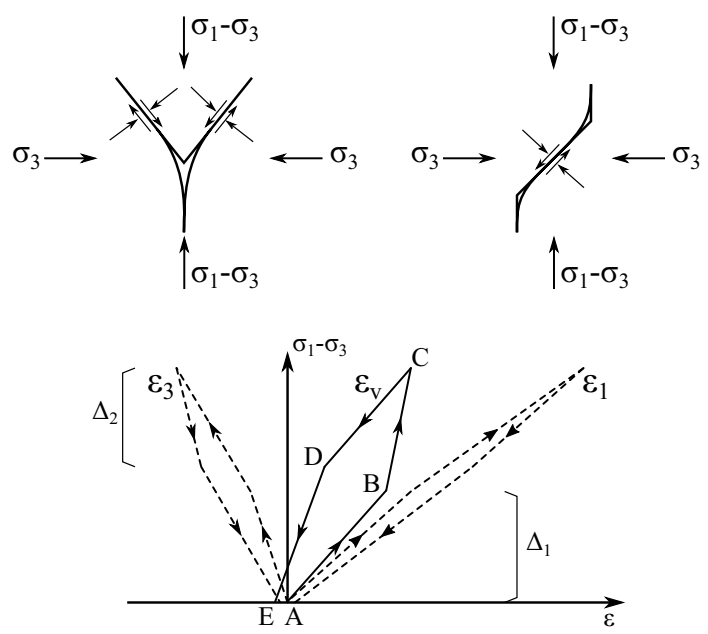

Fig. 13 Simple frictional model dilatant hysteresis, after (Scholz and Kranz 1974; Zoback and Byerlee 1975)

(Zoback and Byerlee 1975). Energy is dissipated both in frictional work and to open the cracks. This explains the opening-closing-opening pattern observed in Fig. 2. The large opening of the first cycles is due to the energy consumed for crack growth, which stabilises after few cycles. During the closing phase, the frictional work is dominant. Crack opens and closes with almost no extension. When the specimen is close to failure, crack growth becomes dominant again, involving increasing hysteresis of the cycles.

A similar model integrating opening or closing of existing cracks is developed in David et al. (2012). It clearly describes the hysteresis observed at low confinement and the evolution of the Young modulus. However, it does not take into account crack generation or coalescence.

These conceptual models are able to explain qualitatively most of the typical results detailed in Sect. 3. Fatigue mechanism resulting in wear of the cracks and contacts between rock grains could be added by assuming a progressive degradation of friction coefficient along the edges of the crack. However, it is impossible to quantify any fatigue strength or time evolution of deformation. In addition, some delayed or creep-like phenomena [upon constant load (Fan et al. 2016, 2017)] described further are not taken into account. However, this is an interesting starting point to derive micro-macro-mechanical models such as those described in Zhu et al. (2008) and Pouya et al. (2016).

\subsection{Fatigue Limit}

It is shown that rock specimens cyclically loaded with an amplitude lower than their monotonic strength fail. A simple way to illustrate the fatigue effect on the resistance is to relate the maximum stress applied to the number of cycles necessary before failure. Such results are termed $S-N$ or Wöhler curves and are common for engineers (Schijve 2003) whatever the material. The fatigue limit or fatigue strength may be defined as the stress amplitude for which there is no failure of the specimen, i.e. the fatigue life becomes infinite (Schijve 2003).

Figure 14 summarises results of $S-N$ curves published in the literature. Different materials and types of experiments (uniaxial, triaxial, Brazilian) are superposed. However, freeze-thaw or thermal loading is excluded, and loading frequency is kept low. Data from Jamali Zavareh et al. (2017) follow a different tendency, probably due to the nonconventional methodology and are not reported. The number of cycles to failure $\mathrm{N}$ is related to the normalised ratio of maximum cyclic stress $\sigma_{\max }$ to monotonic strength $\sigma_{\text {mon. }}$. All fatigue limits reported are listed in "Appendix".

Results presented in Fig. 14 are indeed quite variable. A linear regression is often adopted to describe $S-N$ curve in $\log _{10}$ basis (Schijve 2003), leading to

$\frac{\sigma_{\max }}{\sigma_{\operatorname{mon}}}=0.9455 \log _{10} N-0.0278$.

The standard deviation is equal to 0.0650 . Despite variations around the regression line, the trend is clear. A fatigue limit seems to exist for rock materials. Depending on the tested material, it ranges from 0.75 to 0.9 for one million of cycles. Based on this literature, if no data are available on a particular rock material, a fatigue limit of 0.7 times the monotonic strength may be used. This limit should be used cautiously since the estimated fatigue limit mostly depends on the patience of observers. Failure may occur for a lower stress but also more than one million of cycles. However, a million of cycles should be sufficient to encompass most applications of rock engineering.

$S-N$ curves are very synthetic, simple and fatigue limit may be directly used in design methods. However, they are strongly dependent on experimental conditions even for a

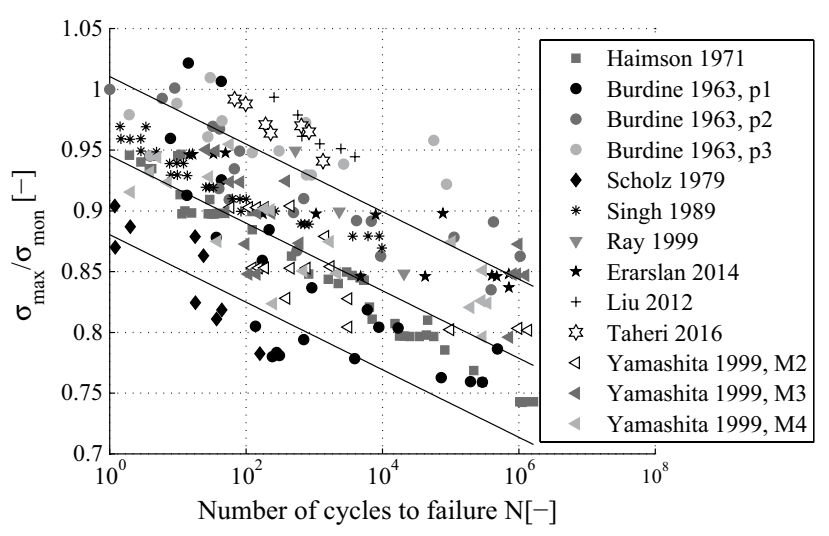

Fig. $14 S-N$ curves for different material and types of tests, constant amplitude 
single material, as previously shown in Table 1 . Therefore, a new $S-N$ curve must be elaborated in each situation which is cumbersome and costly. For instance, Fig. 15 exhibits variations of nonlinear $S-N$ curves with confinement for a single material (Burdine 1963). Confinement increases the fatigue limit. Frequency of the applied load (Attewell and Farmer 1973) or intervals without loading between two cycles (Fan et al. 2016) modify results such that the reference to a number of cycles may be questionable. Therefore, some authors attempt to define other fatigue limit.

Attewell and Farmer (1973) and Tien et al. (1990) propose a strain threshold below which the crack propagation is stable. This is consistent with the definition of a monotonic envelope described in Sect. 3.1. Their definition is interesting but more difficult to apply at the scale of earthwork. Some others suggest the use of a dynamic energy criterion (Bagde and Petroš 2005a). Other authors propose to correlate deformation encountered during the first load cycle with the number of cycles to failure (Tien et al. 1990). All of these methods, despite interesting, are sometimes difficult to apply to engineering practice.

Another factor affecting results is the inherent variability of natural materials. The definition of a fatigue limit is based on a normalisation of the applied cyclic amplitude with respect to a monotonic strength. However, this strength may vary a lot between different samples and is unknown a priori for a given specimen. It is also impossible to conduct monotonic and cyclic tests together on a same sample since both tests lead to the failure of the specimen. This uncertainty introduces dispersion of results in the $S-N$ curve.

A method is proposed in Bastian et al. (2014) and Taheri et al. (2016) to estimate the strength of a specimen before applying a cyclic loading and without damaging the sample. The authors observe that the secant Young's modulus

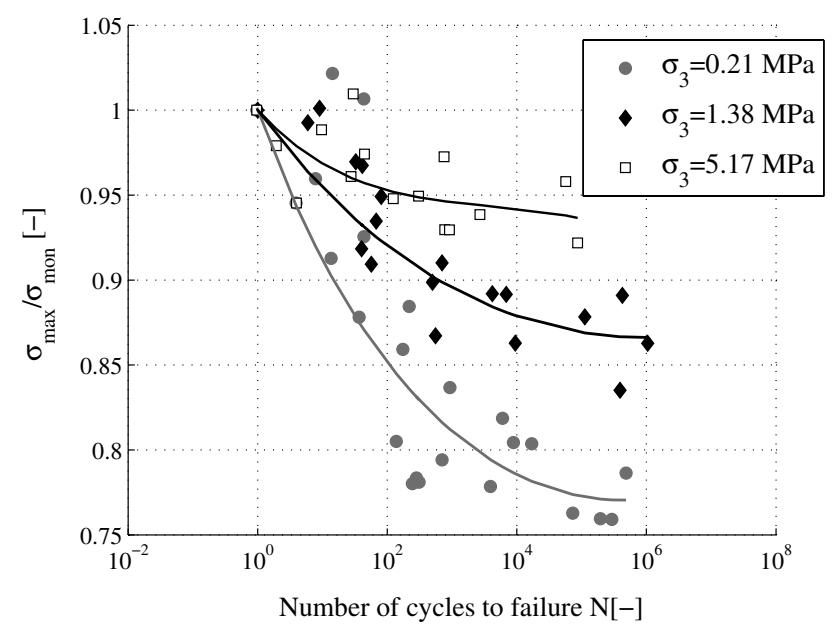

Fig. $15 S-N$ curves for Berea sandstone at three confining pressures (Burdine 1963) encounters a maximum value at deviatoric stress $q_{i d}$ before the failure. They establish that the ratio between this shear stress and the failure stress is a constant for all specimens, namely

$\frac{q_{i d 1}}{q_{f 1}}=\frac{q_{i d 2}}{q_{f 2}}$

This is sketched in Fig. 16 where two stress-strain results corresponding to two different samples monotonically loaded are represented. Therefore, they propose to preload each sample up to the maximum of secant modulus in order to obtain $q_{i d 2}$ and estimate the strength $q_{f 2}$ by comparison with a previous monotonic test providing $\left(q_{i d 1}, q_{f 1}\right)$. The secant modulus is defined according to

$E_{\mathrm{sec}}=\frac{q}{\epsilon+\epsilon_{0}}$,

where $q$ is a deviatoric stress, $\epsilon$ is a strain and $\epsilon_{0}$ is an offset supposed to reduce the variability of results.

This method is quite interesting but should still be applied to other rock materials/experimental set-ups to be validated. Particularly, it should be proven that the samples are not damaged by this preloading. The underlying hypothesis is that stress-strain relations are homothetic for samples of a given material loaded in identical conditions. Variations of the strength parameters depend only on heterogeneity. Another possibility would be to compare the first compression part of the cyclic loading and a monotonic test as reported in Fig. 17. Scaling could be carried out based on the initial elastic stiffness or between two point sharing the same tangent stiffness.

Finally, the model developed in David et al. (2012) relates the hysteretic behaviour of the rock sample to few

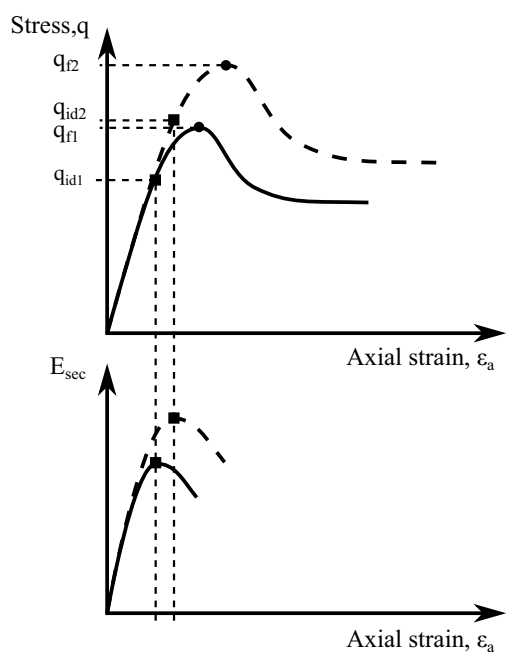

Fig. 16 Use of the secant Young modulus $\left(E_{\text {sec }}\right)$ as an indicator point to predict peak strength, plot of two different monotonic test results for two different samples of a same material 


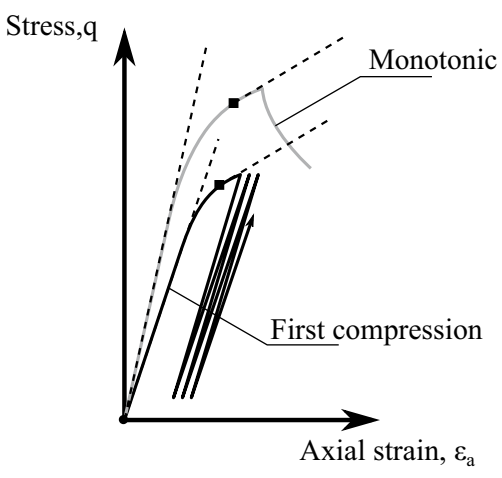

Fig. 17 Estimation of the monotonic strength by comparison of the first compression cycle and a monotonic test

parameters and the damage degree of the material. Subsequently, a back-analysis could provide an estimation of the intact parameters of the material and may be used to normalise the results.

\subsection{Indicator of Fatigue}

Fatigue indicators are derived firstly to analyse, interpret and compare experimental results (Schijve 2003). They consist of a variable, indicating the evolution of a rock sample from its initial state to failure. Therefore, these indicators are also used to predict the evolution of a rock sample; for instance, they define how many cycles of constant amplitude should still be applied before failure. They are a measure of the fatigue degradation process. A suitable damage indicator must fulfil different properties (Xiao et al. 2010), and particularly, it must

- have a clear physical meaning (primary value);

- be measured easily and applied conveniently;

- represent the actual degradation of the material;

- take into account initial degradation from previous loading;
- increase monotonically between zero (intact) and a final value (failure).

Different definitions based on distinct primary measured values are proposed by several authors and are reported in Table 2. The use of residual or vertical deformation is one of the most straightforward definitions since it is directly measured on the rock sample. Elastic or secant modulus is another possible definition requiring few post-processing. More advanced methods such as the measurement of acoustic emissions or wave velocity in the material are also available but require specific devices.

For all of these objectives, the critical step is to compute a priori an initial and final values of the fatigue indicator, corresponding to sample conditions and experimental set-up. None of the definitions are able to compute them simultaneously. If we assume that the monotonic stress-strain path is an envelope for cyclic loading (as established in Sect. 3.1), the maximum residual deformation at failure (for a constant amplitude) may be estimated. However, the initial damage is unknown, since residual deformation is initially equal to zero by definition for any sample.

Most of the indicators successfully help the researcher to analyse and interpret results. They represent the classical three phase behaviour of degradation evolution (decreasing rate, stationary, increasing rate). They are compared in Table 3 with respect to the properties defined before. It is therefore easy to compare results obtained on different samples, a posteriori. It could be interesting to extrapolate results obtained a posteriori to: (1) predict a fatigue indicator evolution law for rock samples or earthwork, (2) derive a complex constitutive law applicable to finite element modelling or (3) monitor already built earthwork.

On the other hand, initial wave velocity or elastic modulus could provide an estimation of the initial damage. However, they are unknown at failure. Both initial and final values are impossible to obtain for acoustic emissions which is therefore not suitable. Volumetric deformation is shown

Table 2 Summary of the different data used to compute a damage variable

\begin{tabular}{ll}
\hline Data nature & References \\
\hline Residual axial deformation & $\begin{array}{c}\text { Tien et al. (1990), Eberhardt et al. (1999), Li et al. (2003), Zhang et al. (2008), Xiao et al. (2010, 2010), Liu } \\
\text { and He (2012), Guo et al. (2012), Wang et al. (2013), Momeni et al. (2015) }\end{array}$ \\
$\begin{array}{l}\text { Residual volumetric deformation } \\
\text { Wave velocity }\end{array}$ & $\begin{array}{l}\text { Xiao et al. (2010) } \\
\text { Elastic/secant modulus }\end{array}$ \\
$\begin{array}{c}\text { Xiao et al. (2010), Wang et al. (2013), Liu and He (2012), Liu et al. (2014), Momeni et al. (2015), Liu et al. } \\
\text { (2017) }\end{array}$ \\
Eberhardt et al. (1999), Jiang et al. (2009), Xiao et al. (2010), Momeni et al. (2015), Karakus et al. (2016) \\
Energy dissipated & Royer-Carfagni and Salvatore (2000), Bagde and Petroš (2005a), Xiao et al. (2010), Momeni et al. (2015), \\
& Liu et al. (2017) \\
Permeability & Schaefer et al. (2015), Mitchell and Faulkner (2008), Wang et al. (2017) \\
\hline
\end{tabular}


Table 3 Summary of the different primary values used to compute a damage variable with respect to the required properties

\begin{tabular}{llllllll}
\hline & Residual $\epsilon_{y}$ & Residual $\epsilon_{v}$ & Wave velocity & Modulus & AE count & Energy & Permeability \\
\hline Physical & $\mathrm{x}$ & $\mathrm{x}$ & $\mathrm{x}$ & $\mathrm{x}$ & $\mathrm{x}$ & $\mathrm{x}$ & $\mathrm{x}$ \\
Measurement & $\mathrm{x}$ & $\mathrm{x}$ & $\mathrm{x}$ & $\mathrm{x}$ & & $\mathrm{x}$ & \\
Initial & & & $\mathrm{x}$ & $\mathrm{x}$ & & & $\mathrm{x}$ \\
Monotonic & $\mathrm{x}$ & & $\mathrm{x}$ & $\mathrm{x}$ & $\mathrm{x}$ & $\mathrm{x}$ & $\mathrm{x}$ \\
Prediction & $\mathrm{x}$ & $\mathrm{x}$ & & & & & \\
\hline
\end{tabular}

to decrease in some cases (Eberhardt et al. 1999) and is not considered in the following.

Finally, Xiao et al. (2010) compare the evolution of different damage indicators related to a same experiment. Their results, reported in Fig. 18, clearly exhibit that two different definitions do not necessarily provide homothetic evolutions. It is therefore impossible to determine what is the true "state" state of the rock material and only a comparison between samples is relevant. In conclusion, it is quite difficult to elaborate a predictive model even for laboratory experiments.

Elastic/secant modulus or wave velocity measurements are a direct measure of damage of the material. Therefore, in this case the fatigue indicator could be directly linked to a damage constitutive law. However, damage is inherently anisotropic since it depends on the orientation of cracks. Shao et al. (2005) develop an anisotropic damage constitutive law for that purpose. However, in this case, a scalar damage variable is insufficient. Therefore, the applicability of a scalar-based constitutive law would be limited. In addition, the choice and the computation method of the modulus may impact the results. Indeed, as reported in Momeni et al. (2015), the secant modulus reproduces the three-stage behaviour observed during fatigue experiments while tangent modulus only provides a scattered decreasing trend.

Permeability evolution is another indirect means of assessing damage in rock samples (Mitchell and Faulkner

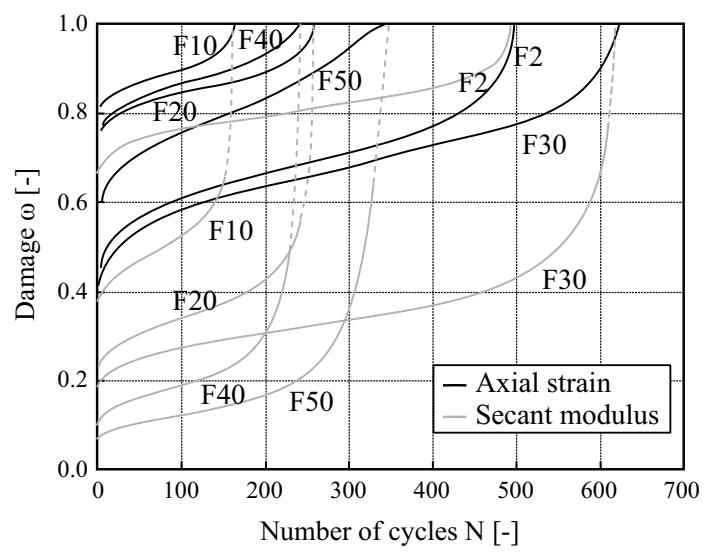

Fig. 18 Two definitions of damage (axial residual strain and axial secant modulus) for uniaxial and triaxial tests (Liu and He 2012)
2008; Schaefer et al. 2015; Wang et al. 2017). It clearly increases monotonically as cracks develop in the sample, in the direction permeability is measured. However, measurement of this physical variable is quite slow especially for low-permeability rock materials (Mitchell and Faulkner 2008). Therefore, this is mainly applicable to low number of cycles loading. In addition, the measurement duration should be negligible with respect to the cycle period; otherwise, delayed effects may affect the results.

Monitoring earthwork is necessary to prevent a catastrophic event. The transition from experimental results to earthwork seems cumbersome since prediction of initial degradation or degradation at failure is even more complex at this scale. Therefore, the definition of an exact state of fatigue and margin of safety is impossible to obtain. However, the increments of the indicator provide relevant information. If the increment per cycle increases, the accelerating phase is reached and will lead to failure in a close future. Acoustic emission, deformation and wave velocity all seem relevant and applicable to monitoring.

In conclusion of this section, should we conclude that fatigue indicators are meaningless? Certainly not, they provide useful means of comparison between experimental results, and they ease their interpretation and highlight the degradation kinetics. In addition, their evolution may be useful for monitoring of earthwork and prevent catastrophic event. However, it is impossible to extrapolate a complex constitutive law or predict the behaviour of complex earth work from a scalar value. It is suggested that a suitable indicator should be based on a combination of different variables rather than on a single one.

\subsection{Relation Between Creep and Fatigue}

The delayed failure of a rock sample subject to a constant applied stress is termed brittle creep (Cruden 1974; Hudson and Harrison 1997; Brantut et al. 2013). Creep and fatigue results are shown to share similar features. They both exhibit time dependant behaviour where deformation rate is firstly decreasing then accelerating before failure. They both show that a sample may be failed for an applied load lower than its monotonic strength. This is termed subcritical crack growth (Atkinson 1984). 
Several mechanisms may be involved in this process such as dissolution, diffusion of ions within cracks, ion exchange or microplasticity. However, the stress corrosion mechanism is recognised to be dominant in many applications (Anderson and Grew 1977; Atkinson 1984; Tomkins 1981; Brantut et al. 2013). It is assumed that stained bonds close to the crack tips react more easily with environmental agents and these bonds are broken at a lower stress level, as shown for silicates in Michalske and Freiman (1982, 1983). The crack propagation is most of the time very slow and seems to be limited by a stress threshold (Anderson and Grew 1977). The influence of the environmental weakening process is reinforced by the presence of water and anisotropy of the material (Nara and Kaneko 2006; Nara et al. 2012).

Schematically, the logarithm of the crack velocity during a subcritical process may be related to the stress intensity factor $K_{\mathrm{I}}$ (Wiederhorn 1967; Anderson and Grew 1977; Ritchie 1999), as depicted in Fig. 19 for a soda-lime-silica glass. For low stress intensity factors, the relation is linear. The kinetics of the crack propagation is thought to be dependent on the chemical reaction between the solid and the environment filling the crack. Crack velocity is independent of $K_{\mathrm{I}}$ for a next range of stress intensity factors. Cracking is then limited by mass transport of reactants to the tip of the crack. This plateau is not observed in any experimental conditions. In this case, it disappears for higher relative humidity. Finally, high velocity rates are observed when the stress intensity factor is close to the critical one, namely

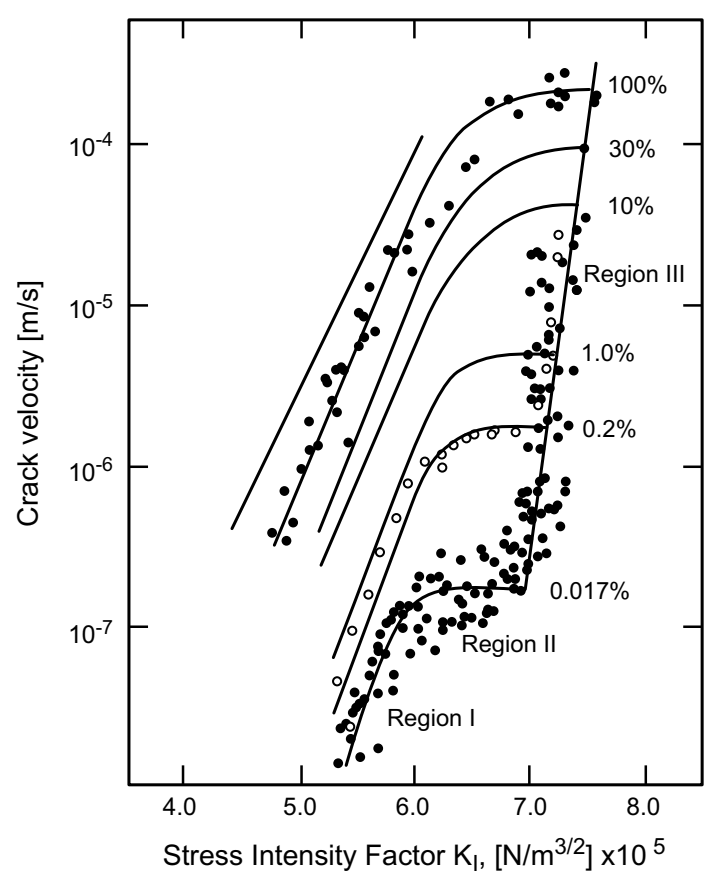

Fig. 19 Effect of relative humidity on crack velocity in a sodalime-silica glass in a nitrogen atmosphere, from Anderson and Grew (1977); Wiederhorn (1967) close to failure. Then the kinetics depends on a mix of corrosive and mechanical fracture.

Such observations and concepts could explain the cyclic behaviour of rock samples subjected to cyclic loading. A study on the cyclic behaviour of ceramic materials (Evans and Fuller 1974) suggests that a stress corrosion process is the origin of the subcritical crack growth without any additional fatigue effect. Therefore, fatigue effect should be considered as a creep behaviour for a constant load equal to the mean load of the cyclic signal. This idea is also proposed for rock materials (Attewell and Farmer 1973), suggesting that the elapsed time between the beginning of the test and failure is more relevant than the number of cycles. Recent studies proves that if time intervals at constant load are imposed between two cycles, the fatigue life is reduced (Fan et al. 2016, 2017), indicating a creep-like phenomenon.

Some other studies identify a distinct fatigue mechanism (Costin and Holcomb 1981; Li et al. 1992; Erarslan and Williams 2012b; Ghamgosar and Erarslan 2016; Ghamgosar et al. 2017) as reported in Sect. 4.1. The different crack processes identified as well as wear along crack edge tend to prove that one or several particular fatigue mechanisms exist. It is particularly shown in Singh (1989) and Momeni et al. (2015) that fatigue life is modified by the cyclic amplitude, for a given maximum stress. This is also consistent with the conceptual model presented before, describing the behaviour of a single crack (Zoback and Byerlee 1975; David et al. 2012). If the number of cycles applied is large, it is likely that the opening/closing and shear mobilisation at the edge of the different cracks will lead to a decrease in friction that could be mobilised (wear).

Interesting results presented in Yamashita et al. (1999) and reported in Fig. 20 compare creep and fatigue $(S-N$
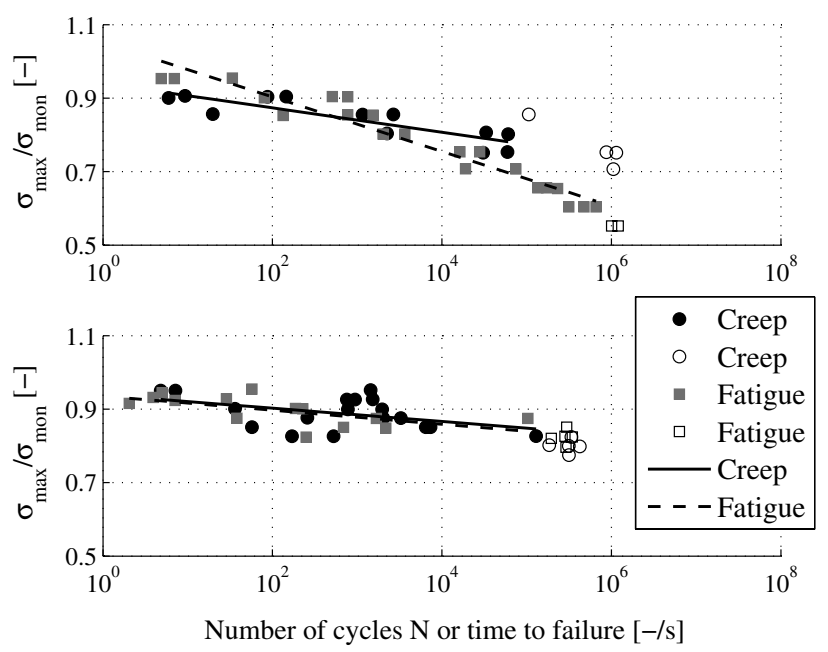

Fig. 20 Relation between fatigue $(1 \mathrm{~Hz})$ and creep tests, Ogino tuff (up) and Kurihashi granite (down), empty markers represent unfailed samples, from Yamashita et al. (1999) 
curve, $1 \mathrm{~Hz}$ ) results. Four materials are tested in this paper, and two are reproduced here. For two materials (granite is depicted in Fig. 20 bottom), creep and fatigue results are remarkably close to each other, sharing a similar fatigue/ creep limit and even $S-N$ curve. For two others (tuff is depicted in Fig. 20 top), slope of the linear regression is different in creep and fatigue. Therefore, this correlation depends probably on the material and mineralogy.

Finally, it is shown in Brantut et al. (2014) that monotonic displacement-controlled tests act as an envelope for creep tests. In other words, failure occurs when the stress-strain curve of creep test intersects the one of monotonic test. This is similar to previous observations during cyclic loading.

It could then be concluded that a fatigue mechanism distinct of the stress corrosion process exists. However, stress corrosion behaviour should not be neglected. They probably interact and should be both taken into account in the result interpretation, depending on the experimental/in-situ conditions.

The type of rock material and grain size probably play an preponderant role in both processes (Prikryl et al. 2003; Heap et al. 2010; Erarslan 2016). As reported in Erarslan and Williams (2012b), each grain may act as an indenter and the magnitude of the fatigue process is likely to depend on the stress amplitude. Grain characteristics are also proven to be central in the stress corrosion process since most cracks initiate at their boundaries (Atkinson 1984). Subsequently, some studies conclude that stress corrosion dominates at high mean stress and low amplitude, while fatigue mechanism is preponderant at high amplitude and low mean stress (Scholz and Koczynski 1979; Costin and Holcomb 1981).

Increasing frequency is shown to increase the number of cycles to failure (Attewell and Farmer 1973; Tien et al. 1990; Ma et al. 2013; Momeni et al. 2015). Indeed, rock strength is inherently strain rate dependent (Zhang et al. 2000; Brantut et al. 2014). Therefore, low frequencies are more likely to enable delayed crack propagation at high stress due to stress corrosion, while high frequencies are more favourable to fatigue mechanisms.

Water and temperature are likely to enhance the stress corrosion effects as previously reported (Atkinson 1984; Kranz et al. 1982). Strength reduction for water saturated samples with respect to dry ones is reported in Baud et al. 2000 due to a decrease in fracture energy and slight drop of friction coefficient. This strength reduction is not identical for all rock types and may depend on the rock mineralogy and especially the clay content, as reported in Hawkins and Mcconnell (1992) and Morales Demarco et al. (2007) for sandstones. Finally, water may have an active weathering role by dissolving bonds between grains within the material (Ciantia et al. 2014). All of these factors should enhance the stress corrosion process active during cyclic loading.

Fatigue and stress corrosion processes are very complex, intricate and depend on many parameters. To date, there is no criterion allowing to distinguish between their respective effects on crack damage evolution. They are most of the time considered separately, and further studies combining both types of tests should be carried out to highlight their respective effects.

\subsection{Kaiser Effect}

The Kaiser effect is a well-known phenomenon in metallurgy (Kaiser 1950) but also in rock mechanics (Lockner 1993; Holcomb 1993; Lavrov 2003). It states that if a sample is subjected to a cyclic stress history, no acoustic emission occurs over a cycle until the applied stress exceeds the maximum previously applied stress. Therefore, monitoring of acoustic emissions during loading of a rock sample allows to assess the stress history of a geomaterials at the laboratory scale (Li and Nordlund 1993) or even at the regional scale (Heimisson et al. 2015). This phenomenon is quite complex and influenced by many factors such as water content, temperature, loading rate, confinement. The interested reader should refer to (Lavrov 2003), while the following focuses on its relation with cyclic loading.

The classical Kaiser effect is observed by several authors during damage-controlled tests, among which (Li and Nordlund 1993; Gatelier et al. 2002; Lavrov 2001; Lavrov et al. 2002). Heap et al. (2009) observe a different manifestation of the Kaiser effect where acoustic emissions are recorded also during a part of the unloading. Their detection starts again at the stress where they stopped rather than at the previous peak stress. This effect is attributed to a delayed crack process. On the other hand, a study questions this phenomenon for the uniaxial cyclic loading of rock (Sondergeld and Estey 1981). Deviations from the classical definition are also identified in Rao and Ramana (1992) where the number of acoustic emissions does not decrease at constant cyclic loading amplitude. Similarly, Trippetta et al. (2013) observe an almost constant number of acoustic emissions during successive cycles in triaxial experiments. This is attributed to two competing processes: dilative microcracking and compacting pore collapse.

The classical interpretation of the Kaiser effect is that no additional damage is generated for cycles whose maximum stress is lower than the previous peak stress (Heap et al. 2009). This definition is in good agreement with observations of damage-controlled tests where few cycles are applied, and there is a significant increase in stress amplitude between cycles. On the contrary, this interpretation seems contradictory with fatigue experiments where a large 
number of cycles are applied. Indeed, reported experiments clearly exhibit a damaging process, while the maximum stress applied is constant.

There are different explanations to this apparent paradox. Firstly, a part of the fatigue mechanism is probably related to crack wear, generating low-amplitude acoustic emissions. A second possibility is a very slow crack growth without acoustic emission as suggested by Anderson and Grew (1977). Such low-amplitude events could be neglected due to a detection threshold in the post-processing (Antonaci et al. 2012). Subsequently, more research is necessary to investigate the relation between acoustic emissions and fatigue mechanism.

\subsection{Link Between Experimental Set-Up and Objectives}

The previous sections list and comment experimental setups, observations and interpretations related to fatigue loading of rock materials. A summary linking all of them is proposed in Fig. 21. The objective is to help researchers or practitioners to plan efficiently an experimental work for a particular purpose.

This flowchart is separated between design and fundamental research objectives. The limit between is indeed less obvious. However, a design purpose is defined as a characteristic value or result that is directly used to derive the strength of an earthwork. Fundamental research encompasses experiments allowing calibration of complex constitutive laws (not simply friction angle and/or cohesion), investigation of concepts such as Kaiser effects or micromechanical origin of fatigue. A typical reference for each application is provided except for pumped storage hydroelectricity (PSHE) which is currently under investigation.

\section{Conclusions and Perspectives}

\subsection{Summary}

This paper lists and classifies the main documents published on the cyclic/fatigue behaviour of rock materials. Typical results observed and main features of mechanical fatigue are detailed. It provides a comprehensive insight on experimental results and methods to other researchers for the design of new experiments or development of constitutive models. Finally, different concepts used to interpret these results are reviewed and their limitations are pointed out, highlighting new directions for applied research work.

The main cause of fracture upon cyclic loading is the progressive decohesion and loosening of the material. They are due to the microcracks propagating or initiating within the rock material before coalescence of a final macrocrack. Stress corrosion and fatigue mechanisms are highlighted to be responsible of the subcritical crack of rock specimens, namely the cyclic strength of rock samples is proven to be lower than the monotonic one. Both mechanisms probably occur simultaneously, stress corrosion dominating at high mean stress while fatigue mechanism is preponderant for high-cycle amplitude.

Typical results reveal different failure modes between monotonic (macrocrack) and cyclic (fragments and dust) experiments. Stress-strain cyclic relations exhibit hysteresis loops that can be explained by a simple frictional model. Energy is dissipated cycle after cycle in frictional work and crack opening. Residual deformation accumulates progressively and is similar to that observed in brittle creep behaviour. The crack growth opening dominates at the beginning and the end, while frictional work is mainly responsible for energy dissipation during the steady stage.
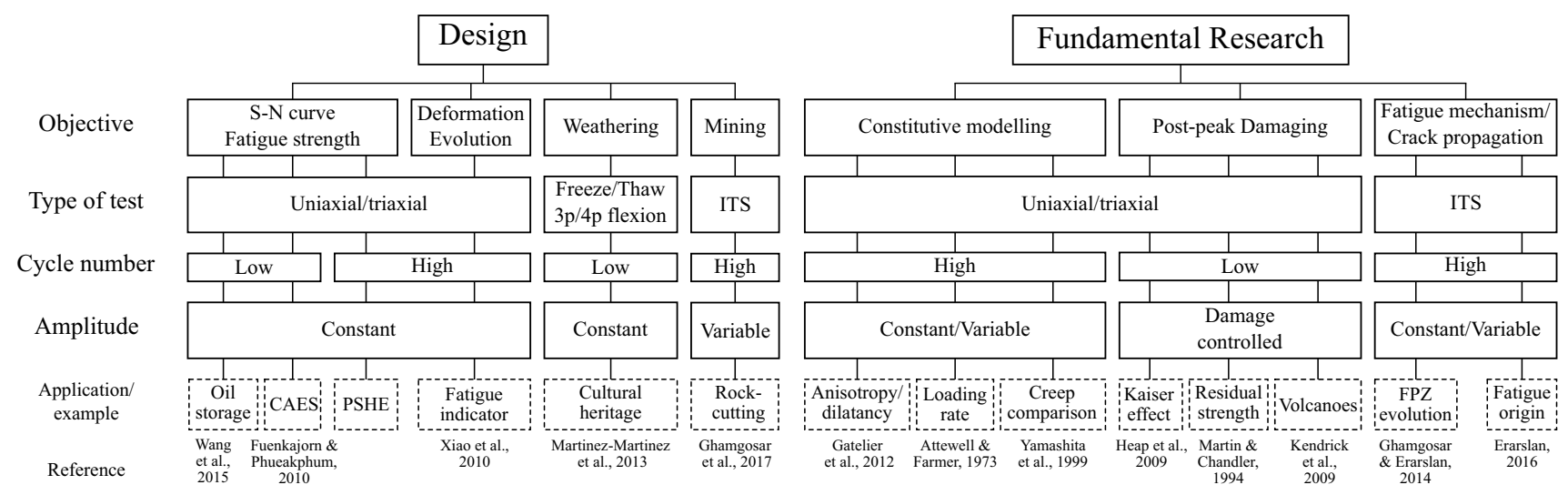

Fig. 21 Flowchart for the choice of an experimental set-up, CAES—compressed air energy storage, PSHE—pumped storage hydroelectricity, ITS—indirect tensile strength, FPZ—fracture process zone 
The progressive degradation affects the stiffness of the specimen which echoes the accumulation of residual deformation in a three-stage fashion. However, the behaviour of the rock specimen is highly anisotropic, especially at low confinement. Therefore, it is not straightforward to describe the evolution of a single stiffness. Consequently, to the microfracturing process, a stress-induced anisotropy is superposed to the initial one, generating a clear dilatancy due to longitudinal cracks. It is more marked than during monotonic experiments due to the repeated cycles, each generating or propagating more microcracks.

Monotonic post-peak behaviour and acoustic emission records are useful in the interpretation of the cyclic experiments. The first one is found to be an envelope or failure locus for the cyclic stress-strain relation. The second is correlated with the evolution of damage within the rock specimen, providing more information than the sole measurement of deformation.

The fatigue limit is one of the most important variables derived from cyclic experiments. It ensures theoretically that if the cyclic stress applied to the rock material lies below this threshold, the material should never fails. However, such a criterion is dependent on the loading conditions (confinement, type of test, frequency, etc.) and is very costly to derive.

Fatigue indicators are used in different studies to compare results from different samples. They provide a useful means of interpretation and understanding of the physical phenomena. Their evolution may be useful to monitor earthwork. However, it is not possible to obtain from these indicators more than they are able to provide. The initial degradation or exact prediction of failure kinetic is impossible to obtain from a single value. It seems unrealistic to formulate a complex constitutive law from a single value evolution, especially for highly anisotropic rocky materials.

Finally, a flowchart is proposed to design experimental campaigns. Depending on the research or practical objectives, different experimental set-ups should be preferred. Different combinations and representative references are proposed.

\subsection{Perspectives}

The relation between creep and fatigue is shown to be extremely close. It is recognised that creep and fatigue mechanisms act together during cyclic loading of rock materials. However, external conditions activating one or two mechanisms are still unknown. We are not able to predict which is the dominant mechanism, if they interact and how. The first direction for further research, which is the most fundamental, would be to identify the causes of the fatigue mechanism. The first hypothesis that should be verified is its uniqueness whatever the conditions and fracture mode.
Several hypotheses are formulated such as a wear of the crack sides or the presence of stiff grains acting as indenters. From that basis, the study of the interaction with stress corrosion and influence of other variables, such as confinement, may be investigated.

Limitations of the classical definition of a fatigue strength are highlighted. The computed value is often related to its particular experimental conditions and is difficult to generalise to other conditions. $S-N$ curves despite useful provide only partial information, and the number of cycles is shown to be dependent on frequency. Therefore, a new concept encompassing the frequency and confinement effects shall be derived. A strain-based definition (Attewell and Farmer 1973; Tien et al. 1990) seems an interesting concept to use for constitutive laws. The relation to the energy deficit similar to creep (Brantut et al. 2014) is another direction of research.

The second challenge is related to the inherent inhomogeneity of the material. The impossibility to predict accurately the monotonic strength of a sample introduces a sometimes large dispersion in the results. A proposed method related to the evolution of the secant modulus constitutes an interesting starting point (Bastian et al. 2014; Taheri et al. 2016) but still need to be validated and generalised to other materials.

The definition of a reliable fatigue indicator is an important issue, especially for monitoring existing work and numerical modelling. The potential indicators previously described almost always fail to fulfil all conditions stated in the definition. The major issues are the definition of the initial degradation and prediction of measured physical parameter at failure. In addition, this indicator should take into account degradations resulting from different cyclic amplitudes, such as the Miner rule (Miner 1945), which has not yet been investigated. Due to the complexity and anisotropy of rocky materials, the combination of several physical variables would probably provide the best results to monitor earthworks.

Some others factors affecting the observations are not or almost not investigated. The anisotropy influence on the fatigue life is one of them. Strata orientation clearly acts as a weakness plane (Gatelier et al. 2002). However, pore geometry and orientation between the pores and the direction of loading may also generate anisotropy (Bubeck et al. 2017; Griffiths et al. 2017), especially in volcanic rocks. The relation to the pore or initial crack orientation is particularly relevant since the fatigue process is inherently related to movement of the cracks. Considering adequately the anisotropy implies the use of more strain gauges. The observed dispersion of strength results should be reduced by considering properly their principal directions.

Moisture content and water effects are also important, especially if hydromechanical coupled problems are investigated. Some clues indicate that the water saturation should not be neglected (Tien et al. 1990; Bagde and Petroš 2005a), and it is demonstrated that saturated samples may have a 
lower strength than dry samples (Baud et al. 2000; Li et al. 2003). In addition, the influence of water in the stress corrosion or chemical processes indicates this parameter should be taken into account especially when large number of cycles are investigated.

Finally, the last issue is the extrapolation of the properties determined in laboratory to the whole rock mass. This issue is not limited to the cyclic behaviour but rather to rock mechanics in general (Hoek and Brown 1997). However, this is also critical in fatigue engineering where it is shown that heterogeneities and initial flaws create good starting point for fractures. Moreover, only few studies explicitly deal with this problem from the cyclic point of view (Le et al. 2014). It is essential to settle this problem to allow a relevant modelling of real applications. The development of quality factors such as Rock Mass Rating (RMR) assessing the sensitivity of a rock mass to fatigue would be an interesting research axis.

Acknowledgements This work is supported by the Walloon Region (Belgium) through SMARTWATER project. The authors would like to gratefully acknowledge Pr. Imai for providing useful papers and references as well as Pr. Michael Heap for providing original figures and data.

\section{Appendix: List of Papers}

\begin{tabular}{|c|c|c|c|c|c|c|}
\hline References & Material & Frequency, rate & Type & $\mathrm{N} \max$ & Fatigue limit & Load signal \\
\hline Grover et al. (1950) & Limestone & - & Uniaxial & - & 0.65 & Constant \\
\hline Shreiner and Pavlova (1958) & - & - & - & - & - & - \\
\hline Burdine (1963) & Sandstone & $15-50 \mathrm{~Hz}$ & Uniaxial, triaxial & $1 \times 10^{6}$ & 0.74 & Constant \\
\hline Haimson and Kim (1971) & Marbre & $2-4 \mathrm{~Hz}$ & Uniaxial & $1 \times 10^{6}$ & 0.75 & Constant \\
\hline Attewell and Farmer (1973) & Limestone & $0.3-20 \mathrm{~Hz}$ & Uniaxial & $4.1 \times 10^{4}$ & - & Constant \\
\hline Brown and Hudson (1974) & Gypsum plaster & $0.5-2 \mathrm{~Hz}$ & Uniaxial & $1.4 \times 10^{4}$ & - & Constant \\
\hline Scholz and Kranz (1974) & Granite & $1 \times 10^{-5} / \mathrm{s}$ & Uniaxial & $2 \times 10^{1}$ & - & Constant \\
\hline Rajaram (1981) & Westerly granite & $1 \mathrm{~Hz}$ & Uniaxial & $1 \times 10^{6}$ & 0.73 & Constant \\
\hline Singh (1989) & Sandstone & $1 \mathrm{~Hz}$ & Uniaxial & $1 \times 10^{4}$ & 0.87 & Constant \\
\hline Tien et al. (1990) & Sandstone & $0.1-1 \mathrm{~Hz}$ & Triaxial & $1 \times 10^{3}$ & - & Constant \\
\hline Zhenyu and Haihong (1990) & Sandstone, marble & $0.0019-0.005 \mathrm{~Hz}$ & Uniaxial & - & - & $\begin{array}{l}\text { Constant, } \\
\text { ramp }\end{array}$ \\
\hline Li et al. (1992) & Sandstone & $0.5 \mathrm{~Hz}$ & Brazilian & $3 \times 10^{4}$ & - & Constant \\
\hline Martin and Chandler (1994) & Granite & $0.75 \mathrm{Mpa} / \mathrm{s}$ & Uniaxial, triaxial & - & - & Damage \\
\hline Celestino et al. (1995) & Granite & $7 \mathrm{kN} / \mathrm{min}$ & Brazilian & $2.3 \times 10^{1}$ & - & Constant \\
\hline Eberhardt et al. (1999) & Granite & $0.25 \mathrm{MPa} / \mathrm{s}$ & Uniaxial & - & - & Damage \\
\hline Yamashita et al. (1999) & $\begin{array}{l}\text { Tuff, sandstone, marble, } \\
\text { granite }\end{array}$ & $1 \mathrm{~Hz}$ & Uniaxial & $1 \times 10^{6}$ & $0.55-0.80$ & Constant \\
\hline $\begin{array}{l}\text { Royer-Carfagni and Salva- } \\
\text { tore }(2000)\end{array}$ & Marble & $1-2 \mathrm{Mpa} / \mathrm{s}$ & Uniaxial & $1.8 \times 10^{2}$ & - & Constant \\
\hline Cattaneo and Labuz (2001) & Marble & - & Flexion & - & - & Damage \\
\hline Lavrov (2001 & Limestone & - & Uniaxial, Brazilian & - & - & Damage \\
\hline Gatelier et al. (2002) & Sandstone & $0.025-0.2 \mathrm{~Hz}$ & Uniaxial, triaxial & - & - & Damage \\
\hline Li et al. (2003) & Sandstone & $2-20 \mathrm{~Hz}$ & Uniaxial & - & - & Damage \\
\hline Åkesson et al. (2004) & Granite & $4 \mathrm{~Hz}$ & Uniaxial & $3.5 \times 10^{4}$ & 0.6 & Constant \\
\hline Ko (2005) & Gypsum & $0.5 \mathrm{~Hz}$ & Uniaxial & $4 \times 10^{3}$ & - & Constant \\
\hline Bagde and Petroš (2005a) & Sandstone & $0.1-1-10 \mathrm{~Hz}$ & Uniaxial & - & - & Ramp \\
\hline Zhang et al. (2008) & Reconstituted & $0.02,2,1 \mathrm{~Hz}$ & Uniaxial & - & - & Constant \\
\hline Heap and Faulkner (2008) & Granite & $2.5 \mathrm{MPa} / \mathrm{min}$ & Uniaxial & - & - & Damage \\
\hline $\begin{array}{l}\text { Mitchell and Faulkner } \\
\text { (2008) }\end{array}$ & Granite, granodiorite & $3.3 \times 10^{-4} \mathrm{~Hz}$ & Triaxial & $1 \times 10^{1}$ & - & Constant \\
\hline Xiao et al. (2009) & Granite & $0.2 \mathrm{~Hz}$ & Uniaxial & - & - & Constant \\
\hline Heap et al. (2009) & Basalt & - & Uniaxial & - & - & Damage \\
\hline Heap et al. (2010) & Basalt, sandstone, granite & $7 \times 10^{-6} \mathrm{~s}^{-1}$ & Triaxial & - & - & Damage \\
\hline Xiao et al. (2010) & Granite & $0.2 \mathrm{~Hz}$ & Uniaxial & $3 \times 10^{3}$ & - & Constant \\
\hline Xiao et al. (2010) & Granite & $0.2 \mathrm{~Hz}$ & Uniaxial & $1 \times 10^{3}$ & - & Constant \\
\hline
\end{tabular}




\begin{tabular}{|c|c|c|c|c|c|c|}
\hline References & Material & Frequency, rate & Type & $\mathrm{N} \max$ & Fatigue limit & Load signal \\
\hline $\begin{array}{l}\text { Fuenkajorn and Phueak- } \\
\text { phum (2010) }\end{array}$ & Salt & $0.001-0.03 \mathrm{~Hz}$ & Triaxial & $1 \times 10^{3}$ & - & Constant \\
\hline $\begin{array}{l}\text { Erarslan and Williams } \\
(2012 b)\end{array}$ & Tuff & $1 \mathrm{~Hz}$ & Brazilian & $1 \times 10^{5}$ & 0.7 & $\begin{array}{l}\text { Constant, } \\
\text { ramp }\end{array}$ \\
\hline $\begin{array}{l}\text { Erarslan and Williams } \\
\text { (2012a) }\end{array}$ & Brisbane & $1 \mathrm{~Hz}$ & Brazilian & $2.9 \times 10^{3}$ & - & Ramp \\
\hline Liu and He (2012) & Sandstone & $1 \mathrm{~Hz}$ & Triaxial & $6.2 \times 10^{2}$ & - & Constant \\
\hline Guo et al. (2012) & Salt & $1 \mathrm{~Hz}$ & Uniaxial & $1.5 \times 10^{4}$ & 0.75 & Constant \\
\hline David et al. (2012) & Sandstone, granite & $2 \times 10^{-6} \mathrm{~s}^{-1}$ & Uniaxial & - & - & Damage \\
\hline Wang et al. (2013) & Granite & $50 \mathrm{~N} / \mathrm{s}$ & Triaxial & - & - & Damage \\
\hline Ma et al. (2013) & Salt & $0.025-0.1 \mathrm{~Hz}$ & Triaxial & $8.5 \times 10^{2}$ & - & Constant \\
\hline Song et al. (2013) & Salt & $0.36-10 \mathrm{kN} / \mathrm{s}$ & Uniaxial & $6 \times 10^{2}$ & - & Constant \\
\hline Trippetta et al. (2013) & Evaporites & $7 \times 10^{-6} \mathrm{~s}^{-1}$ & Uniaxial & - & - & Damage \\
\hline Faoro et al. (2013) & Granite, basalt & $5 \times 10^{-6} \mathrm{~m} / \mathrm{s}$ & Triaxial & - & - & Damage \\
\hline Kendrick et al. (2013) & Volcanic & $1 \times 10^{-5} \mathrm{~s}^{-1}$ & Uniaxial & - & - & Damage \\
\hline Bastian et al. (2014) & Sandstone & $1-6 \mathrm{~mm} / \mathrm{min}$ & Uniaxial, triaxial & $1 \times 10^{2}$ & - & Constant \\
\hline Erarslan et al. (2014) & Tuff & - & Brazilian & $8 \times 10^{5}$ & 0.68 & $\begin{array}{l}\text { Constant, } \\
\text { ramp }\end{array}$ \\
\hline $\begin{array}{l}\text { Nejati and Ghazvinian } \\
\text { (2014) }\end{array}$ & $\begin{array}{l}\text { Marble, sandstone, lime- } \\
\text { stone }\end{array}$ & $1 \mathrm{~Hz}$ & Brazilian & $3 \times 10^{3}$ & $0.6 / 0.7 / 0.8$ & Constant \\
\hline Le et al. (2014) & Sandstone & $1 \mathrm{~Hz}$ & Flexion & $5.5 \times 10^{3}$ & - & Constant \\
\hline Liu et al. (2014) & Salt & $1 \mathrm{~Hz}$ & Uniaxial & - & - & Damage \\
\hline Pola et al. (2014) & $\begin{array}{l}\text { Lava, pyroclastic, tuff, } \\
\text { ignimbrite }\end{array}$ & $4 \mathrm{~mm} / \mathrm{h}$ & Uniaxial & - & - & Damage \\
\hline Ni (2014) & Granite & $0.01-1 \mathrm{~Hz}$ & Uniaxial & - & - & Constant \\
\hline Momeni et al. (2015) & Granite & $0.1-5 \mathrm{~Hz}$ & Uniaxial & $2.4 \times 10^{3}$ & - & Constant \\
\hline Voznesenskii et al. (2015) & Limestone, gabbro, marble & - & Uniaxial & 200 & - & Constant \\
\hline Yang et al. (2015) & Sandstone & $0.08 \mathrm{~mm} / \mathrm{min}$ & Triaxial & - & - & Damage \\
\hline Schaefer et al. (2015) & Basalt & $10^{-5} \mathrm{~s}^{-1}$ & Uniaxial & - & - & Damage \\
\hline Voznesenskii et al. (2016) & Gypsum & - & Uniaxial & $1 \times 10^{2}$ & - & Constant \\
\hline Taheri et al. (2016) & Sandstone & $0.5 \mathrm{~mm} / \mathrm{min}$ & Triaxial & $2.2 \times 10^{3}$ & - & $\begin{array}{r}\text { Constant, } \\
\text { damage }\end{array}$ \\
\hline $\begin{array}{l}\text { Ghamgosar and Erarslan } \\
\text { (2016) }\end{array}$ & Tuff & $1-5 \mathrm{~Hz}$ & Brazilian & - & - & $\begin{array}{l}\text { Ramp, dam- } \\
\text { age }\end{array}$ \\
\hline Erarslan (2016) & Tuff & - & Brazilian & - & - & $\begin{array}{l}\text { Constant, } \\
\text { ramp }\end{array}$ \\
\hline Wang et al. (2016) & Salt & $0.05 \mathrm{kN} / \mathrm{s}$ & Brazilian & $5.2 \times 10^{3}$ & - & Damage \\
\hline Fan et al. (2016) & Salt & $2 \mathrm{kN} / \mathrm{s}$ & Uniaxial & $9 \times 10^{1}$ & - & Interval \\
\hline Jiang et al. (2016) & Salt & $2 \mathrm{kN} / \mathrm{s}$ & Uniaxial & $6 \times 10^{1}$ & - & Interval \\
\hline Song et al. (2016) & Sandstone & $0.12 \mathrm{~mm} / \mathrm{min}$ & Uniaxial & - & - & Damage \\
\hline Meng et al. (2016) & Sandstone & $0.5-4 \mathrm{kN} / \mathrm{s}$ & Uniaxial & - & - & Damage \\
\hline Karakus et al. (2016) & Sandstone & - & Uniaxial & $1 \times 10^{4}$ & - & Constant \\
\hline Fan et al. (2017) & Salt & $2 \mathrm{kN} / \mathrm{s}$ & Uniaxial & $9 \times 10^{1}$ & - & Interval \\
\hline Jobli et al. (2017) & Granite & $1 \mathrm{~Hz}$ & Uniaxial & $1 \times 10^{2}$ & - & Constant \\
\hline Yang et al. (2017) & Marble & $0.02 \mathrm{~mm} / \mathrm{s}$ & Triaxial & - & - & Damage \\
\hline Wang et al. (2017) & Sandstone & - & Triaxial & - & - & Damage \\
\hline Ghamgosar et al. (2017) & Tuff/monzonite & $1,5 \mathrm{~Hz}$ & Brazilian & - & - & Ramp \\
\hline Voznesenskii et al. (2017) & Salt & $0.0001-2 \mathrm{~mm} / \mathrm{min}$ & Uniaxial & $\times 10^{2}$ & - & Constant \\
\hline Liu et al. (2017) & Sandstone & $1 \mathrm{~Hz}$ & Brazilian & $8.5 \times 10^{2}$ & - & Constant \\
\hline Liu et al. (2017) & Artificial & $0.01-20 \mathrm{~Hz}$ & Uniaxial & $1.2 \times 10^{3}$ & - & Constant \\
\hline Jamali Zavareh et al. (2017) & Gabbro, onyx, limestone & $5 \mathrm{~Hz}$ & Bending & $>1 \times 10^{6}$ & $0.4-0.6$ & Constant \\
\hline Munoz and Taheri (2017) & Sandstone & $0.18 \times 10^{-4} \mathrm{~s}^{-1}$ & Uniaxial & - & - & Damage \\
\hline
\end{tabular}




\section{References}

Åkesson U, Hansson J, Stigh J (2004) Characterisation of microcracks in the Bohus granite, western Sweden, caused by uniaxial cyclic loading. Eng Geol 72(1-2):131-142. doi:10.1016/j. enggeo.2003.07.001

Alarcon-Guzman A, Leonards G, Chameau J (1989) Undrained monotonic and cyclic strength of sand. J Geotech Eng ASCE 114(10):1089-1109

Anderson O, Grew P (1977) Stress corrosion theory of crack propagation with applications to geophysics. Rev Geophys 15(1):77-104

Antonaci P, Bocca P, Masera D (2012) Fatigue crack propagation monitoring by acoustic emission signal analysis. Eng Fract Mech 81:26-32. doi:10.1016/j.engfracmech.2011.09.017

Atkinson B (1984) Subcritical crack growth in geological materials. J Geophys Res 89(B6):4077. doi:10.1029/JB089iB06p04077

Attewell P, Farmer W (1973) Fatigue behaviour of rock. Int J Rock Mech Min Sci 10:1-9

Attewell P, Sandford M (1974) Intrinsic shear strength of a brittle, anisotropic rock: experimental and mechanical interpretation. Int J Rock Mech Min Sci Geomech Abstr 11(11):423-430

Bagde M, Petroš V (2005) Fatigue properties of intact sandstone samples subjected to dynamic uniaxial cyclical loading. Int J Rock Mech Min Sci 42(2):237-250. doi:10.1016/j.jirmms.2004.08.008

Bagde MN, Petroš V (2005) Waveform effect on fatigue properties of intact sandstone in uniaxial cyclical loading. Rock Mech Rock Eng 38(3):169-196. doi:10.1007/s00603-005-0045-8

Bastian T, Connelly B, Lazo Olivares C, Yfantidis N, Taheri A (2014) Progressive damage of hawkesbury sandstone subjected to systematic cyclic loading. Min Educ Aust J Res Proj Rev 3:7-14

Baud P, Zhu W, Wong T-F (2000) In the brittle faulting regime, damage mechanics models predict that the uniaxial compressive strength scales with presence of water the confined brittle strength the pore will be denoted by Pt. J Geophys Res 105:371-389

Bertuzzi R, Douglas K, Mostyn G (2016) Comparison of intact rock strength criteria for pragmatic design. Int J Geotech Geoenviron Eng. doi:10.1061/(ASCE)GT.1943-5606.0001644

Bieniawski Z (1967) Mechanism of brittle fracture of rock: part II experimental studies. Int J Rock Mech Min Sci 4:407-423

Brantut N, Heap M, Baud P, Meredith P (2014) Rate- and straindependent brittle deformation of rocks. J Geophys Res Solid Earth. doi:10.1002/2013JB010448.Received

Brantut N, Heap M, Meredith P, Baud P (2013) Time-dependent cracking and brittle creep in crustal rocks: a review. J Struct Geol 52:17-43. doi:10.1016/j.jsg.2013.03.007

Brown E, Hudson J (1974) Fatigue failure characteristics of some models of jointed rocks. Earthq Eng Struct Dyn 2:379-386

Bubeck A, Walker R, Healy D, Dobbs M, Holwell D (2017) Pore geometry as a control on rock strength. Earth Planet Sci Lett 457:38-48. doi:10.1016/j.epsl.2016.09.050

Burdine N (1963) Rock failure under dynamic loading conditions. Soc Petrol Eng J 3(01):1-8

Cardani G, Meda A (2004) Marble behaviour under monotonic and cyclic loading in tension. Constr Build Mater 18(6):419-424. doi:10.1016/j.conbuildmat.2004.03.012

Cattaneo S, Labuz J (2001) Damage of marble from cyclic loading. J Mater Civ Eng 13(December):459-465

Celestino T, Bortolucci A, Nobrega C (1995) Determination of rock fracture toughness under creep and fatigue. In: Proceedings of the 35th US symposium on rock mechanics. Reno, New York, pp 147-152

Cho S, Ogata Y, Kaneko K (2003) Strain-rate dependency of the dynamic tensile strength of rock. Int J Rock Mech Min Sci 40(5):763-777
Chow TM, Meglis IL, Young RP (1995) Progressive microcrack development in tests on Lac du Bonnet granite-II. Ultrasonic tomographic imaging. Int J Rock Mech Min Sci 32(8):751-761. doi:10.1016/0148-9062(95)00015-9

Ciantia M, Castellanza R, di Prisco C (2014) Experimental study on the water-induced weakening of calcarenites. Rock Mech Rock Eng 48(2):441-461. doi:10.1007/s00603-014-0603-Z

Cosenza P, Ghoreychi M, Bazargan-Sabet B, de Marsily G (1999) In situ rock salt permeability measurement for long term safety assessment of storage. Int J Rock Mech Min Sci 36:509-526. doi:10.1016/S0148-9062(99)00017-0

Costin LS, Holcomb DJ (1981) Time-dependent failure of rock under cyclic loading. Tectonophysics 79(3-4):279-296. doi:10.1016/0040-1951(81)90117-7

Cruden D (1974) The static fatigue of brittle rock under uniaxial compression. Int J Rock Mech Min Sci Geomech Abstr 11(2):67-73

David E, Brantut N, Schubnel A, Zimmerman R (2012) Sliding crack model for nonlinearity and hysteresis in the uniaxial stress strain curve of rock. Int J Rock Mech Min Sci 52:9-17. doi:10.1016/j. ijrmms.2012.02.001

Eberhardt E, Stead D, Stimpson B (1999) Quantifying progressive prepeak brittle fracture damage in rock during uniaxial compression. Int J Rock Mech Min Sci 36(3):361-380

Erarslan N (2016) Microstructural investigation of subcritical crack propagation and fracture process zone (FPZ) by the reduction of rock fracture toughness under cyclic loading. Eng Geol 208:181190. doi:10.1016/j.enggeo.2016.04.035

Erarslan N, Alehossein H, Williams DJ (2014) Tensile fracture strength of Brisbane tuff by static and cyclic loading tests. Rock Mech Rock Eng 47(4):1135-1151. doi:10.1007/s00603-013-0469-5

Erarslan N, Williams D (2012a) Investigating the effect of cyclic loading on the indirect tensile strength of rocks. Rock Mech Rock Eng 45(3):327-340. doi:10.1007/s00603-011-0209-7

Erarslan N, Williams D (2012) Mechanism of rock fatigue damage in terms of fracturing modes. Int J Fatigue 43:76-89. doi:10.1016/j. ijfatigue.2012.02.008

Evans A, Fuller R (1974) Crack propagation in ceramic materials under cyclic loading conditions. Metall Trans 5:27-33

Fan J, Chen J, Jiang D, Chemenda A, Chen J, Ambre J (2017) Discontinuous cyclic loading tests of salt with acoustic emission monitoring. Int J Fatigue 94:140-144. doi:10.1016/j. ijfatigue.2016.09.016

Fan J, Chen J, Jiang D, Ren S, Wu J (2016) Fatigue properties of rock salt subjected to interval cyclic pressure. Int J Fatigue 90:109_ 115. doi:10.1016/j.ijfatigue.2016.04.021

Faoro I, Vinciguerra S, Marone C, Elsworth D, Schubnel A (2013) Linking permeability to crack density evolution in thermally stressed rocks under cyclic loading. Geophys Res Lett 40(February):2590-2595. doi:10.1002/grl.50436

Fredrich J, Evans B, Wong T (1989) Micromechanics of the brittle to plastic transition in Carrara marble. J Geophys Res 94:41294145. doi:10.1029/JB094iB04p04129

Fuenkajorn K, Phueakphum D (2010) Effects of cyclic loading on mechanical properties of Maha Sarakham salt. Eng Geol 112(14):43-52. doi:10.1016/j.enggeo.2010.01.002

Gatelier N, Pellet F, Loret B (2002) Mechanical damage of an anisotropic porous rock in cyclic triaxial tests. Int J Rock Mech Min Sci 39(3):335-354. doi:10.1016/S1365-1609(02)00029-1

Ghamgosar M, Erarslan N (2016) Experimental and numerical studies on development of fracture process zone (FPZ) in rocks under cyclic and static loadings. Rock Mech Rock Eng 49(3):893-908. doi:10.1007/s00603-015-0793-z

Ghamgosar M, Erarslan N, Williams D (2017) Experimental Investigation of fracture process zone in rocks damaged under cyclic loadings. Exp Mech 57:97-113. doi:10.1007/s11340-016-0216-4 
Gong M, Smith I (2003) Effect of waveform and loading sequence on low-cycle compressive fatigue life of spruce. J Mater Civ Eng 15(February):93-99

Griffiths L, Heap M, Xu T, Chen C-F, Baud P (2017) The influence of pore geometry and orientation on the strength and stiffness of porous rock. J Struct Geol 96:149-160. doi:10.1016/j. jsg.2017.02.006

Grover H, Dehlinger P, McClure G (1950) Investigation of fatigue characteristics of rocks. Technical report, Drilling Research Inc

Guo Y, Yang C, Mao H (2012) Mechanical properties of Jintan mine rock salt under complex stress paths. Int J Rock Mech Min Sci 56:54-61. doi:10.1016/j.ijrmms.2012.07.025

Haimson BC, Kim CM (1971) Mechanical behaviour of rock under cyclic fatigue. In: Cording EJ (ed) Stability of rock slopes. Proceedings of the 13th symposium on rock mechanics. ASCE, New York, pp 845-863

Hale P, Shakoor A (2003) A laboratory investigation of the effects of cyclic heating and cooling, wetting and drying, and freezing and thawing on the compressive strength of selected sandstones. Environ Eng Geosci 9(2):117-130. doi:10.2113/9.2.117

Hashash Y, Hook J, Schmidt B, I-Chiang Yao J (2001) Seismic design and analysis of underground structures. Tunn Undergr Space Technol 16(4):247-293. doi:10.1016/S0886-7798(01)00051-7

Hawkins A, Mcconnell B (1992) Sensitivity of sandstone strength and deformability to changes in moisture content: sandstones studied. Q J Eng Geol 25:115-130. doi:10.1144/GSL. QJEG.1992.025.02.05

Heap M, Faulkner D (2008) Quantifying the evolution of static elastic properties as crystalline rock approaches failure. Int J Rock Mech Min Sci 45:564-573. doi:10.1016/j.ijrmms.2007.07.018

Heap M, Faulkner D, Meredith P, Vinciguerra S (2010) Elastic moduli evolution and accompanying stress changes with increasing crack damage: implications for stress changes around fault zones and volcanoes during deformation. Geophys J Int 183(1):225-236. doi:10.1111/j.1365-246X.2010.04726.x

Heap MJ, Vinciguerra S, Meredith PG (2009) The evolution of elastic moduli with increasing crack damage during cyclic stressing of a basalt from Mt. Etna volcano. Tectonophysics 471(1-2):153160. doi:10.1016/j.tecto.2008.10.004

Heimisson E, Einarsson P, Sigmundsson F, Brandsdóttir B (2015) Kilometer-scale Kaiser effect identified in Krafla volcano, Iceland. Geophys Res Lett 42:7958-7965. doi:10.1002/2015GL065680. Received

Hoek E, Brown E (1997) Practical estimates of rock mass strength. Int J Rock Mech Min Sci 34(8):1165-1186. doi:10.1016/ S1365-1609(97)80069-X

Holcomb D (1993) General theory of the Kaiser effect. Int J Rock Mech Min Sci Geomech Abstr 30(7):929-935

Hudson J, Harrison J (1997) Engineering rock mechanics-an introduction to the principles, 1st edn. Elsevier, Amsterdam

Jamali Zavareh S, Baghbanan A, Hashemolhosseini H, Haghgouei H (2017) Effect of micro-structure on fatigue behaviour of intact rocks under completely reversed load. Anal Numer Methods Min Eng 6:55-62

Jamshidi A, Nikudel M, Khamehchiyan M (2013) Predicting the long-term durability of building stones against freeze-thaw using a decay function model. Cold Reg Sci Technol 92:29-36. doi:10.1016/j.coldregions.2013.03.007

Jiang D, Fan J, Chen J, Li L, Cui Y (2016) A mechanism of fatigue in salt under discontinuous cycle loading. Int J Rock Mech Min Sci 86:255-260. doi:10.1016/j.ijrmms.2016.05.004

Jiang X, Shu-chun L, Yun-qi T, Xiao-jun T, Xin W (2009) Acoustic emission characteristic during rock fatigue damage and failure. Proc Earth Planet Sci 1(1):556-559. doi:10.1016/j. proeps.2009.09.088
Jobli A, Noor M, Tawie R, Hampden A, Julai N (2017) Uniaxial compressive strength of Malaysian weathered granite due to cyclic loading. J Eng Appl Sci 12(14):4298-4301

Kaiser J (1950) An investigation into the occurrence of noises in tensile tests, or a study of acoustic phenomena in tensile tests. Ph.D. thesis, Technische Hochschule Munich

Karakus M, Akdag S, Bruning T (2016) Rock fatigue damage assessment by acoustic emission. In: International conference on geomechanics, geo-energy and geo-resources, September, Melbourne, Australia

Kendrick J, Smith R, Sammonds P, Meredith P, Dainty M, Pallister J (2013) The influence of thermal and cyclic stressing on the strength of rocks from Mount St. Helens, Washington. Bull Volcanol. doi:10.1007/s00445-013-0728-z

Ko T (2005) Crack coalescence in rock-like material under cyclic loading. Ph.D. thesis, Massachusetts Institute of Technology

Kranz R, Harris W, Carter N (1982) Static fatigue of granite at 200. Geophys Res Lett 9(1):1-4. doi:10.1029/GL009i001p00001

Kranz RL (1983) Microcracks in rocks: a review. Tectonophysics 100(1-3):449-480. doi:10.1016/0040-1951(83)90198-1

Kumar A (1968) The effect of stress rate and temperature on the strength of basalt and granite. Geophysics 33(3):501-510

Lavrov A (2001) Kaiser effect observation in brittle rock cyclically loaded with different loading rates. Mech Mater 33(11):669-677. doi:10.1016/S0167-6636(01)00081-3

Lavrov A (2003) The Kaiser effect in rocks: principles and stress estimation techniques. Int J Rock Mech Min Sci 40:151-171. doi:10.1016/S1365-1609(02)00138-7

Lavrov A, Vervoort A, Wevers M, Napier JAL (2002) Experimental and numerical study of the Kaiser effect in cyclic Brazilian tests with disk rotation. Int J Rock Mech Min Sci 39(3):287-302. doi:10.1016/S1365-1609(02)00038-2

Le J, Manning J, Labuz J (2014) Scaling of fatigue crack growth in rock. Int J Rock Mech Min Sci 72:71-79. doi:10.1016/j. ijrmms.2014.08.015

Lee MK, Barr BG (2004) An overview of the fatigue behaviour of plain and fibre reinforced concrete. Cement Concr Compos 26(4):299305. doi:10.1016/S0958-9465(02)00139-7

Li C, Nordlund E (1993) Experimental verification of the Kaiser effect in rocks. Rock Mech Rock Eng 26(4):333-351. doi:10.1007/ BF01027116

Li G, Moelle K, Lewis J (1992) Fatigue crack growth in brittle sandstones. Int J Rock Mech Min Sci 29(5):469-477

Li N, Zhang P, Chen Y, Swoboda G (2003) Fatigue properties of cracked, saturated and frozen sandstone samples under cyclic loading. Int J Rock Mech Min Sci 40(1):145-150. doi:10.1016/ S1365-1609(02)00111-9

Liu E, He S (2012) Effects of cyclic dynamic loading on the mechanical properties of intact rock samples under confining pressure conditions. Eng Geol 125:81-91. doi:10.1016/j.enggeo.2011.11.007

Liu J, Xie H, Hou Z, Yang C, Chen L (2014) Damage evolution of rock salt under cyclic loading in unixial tests. Acta Geotech 9(1):153-160. doi:10.1007/s11440-013-0236-5

Liu Q, Huang S, Kang Y, Liu X (2015) Cold regions science and technology a prediction model for uniaxial compressive strength of deteriorated rocks due to freeze thaw. Cold Reg Sci Technol 120:96-107. doi:10.1016/j.coldregions.2015.09.013

Liu Y, Dai F, Fan P, Xu N, Dong L (2017a) Experimental investigation of the influence of joint geometric configurations on the mechanical properties of intermittent jointed rock models under cyclic uniaxial compression. Rock Mech Rock Eng 50(6):1453-1471. doi:10.1007/s00603-017-1190-6

Liu Y, Dai F, Xu N, Zhao T (2017b) Cyclic flattened Brazilian disc tests for measuring the tensile fatigue properties of brittle rocks cyclic flattened Brazilian disc tests for measuring the 
tensile fatigue properties of brittle rocks. Rev Sci Instrum. doi:10.1063/1.4995656

Lockner D (1993) The role of acoustic emission in the study of rock fracture. Int J Rock Mech Min Sci Geomech Abstr 30(7):883-899

Lockner DA, Byerlee JD, Kuksenko V, Ponomarev A, Sidorin A (1992) Chapter 1 observations of quasistatic fault growth from acoustic emissions. Int Geophys 51:3-31. doi:10.1016/ S0074-6142(08)62813-2

Ma L, Liu X, Wang M, Xu H, Hua R, Fan P, Jiang S, Wang G, Yi Q (2013) Experimental investigation of the mechanical properties of rock salt under triaxial cyclic loading. Int J Rock Mech Min Sci 62:34-41. doi:10.1016/j.ijrmms.2013.04.003

Martin C, Chandler N (1994) The progressive fracture of Lac du Bonnet granite. Int J Rock Mech Min Sci 31(6):643-659

Martin C, Maybee W (2000) The strength of hard-rock pillars. Int J Rock Mech Min Sci 37(8):1239-1246

Martinez-Martinez J, Benavente D, Gomez-Heras M, Marco-Castano L, Garcia-Del-Cura M (2013) Non-linear decay of building stones during freeze-thaw weathering processes. Constr Build Mater 38:443-454. doi:10.1016/j.conbuildmat.2012.07.059

Meglis IL, Chow TM, Young RP (1995) Progressive microcrack development in tests on Lac du Bonnet granite-I. Acoustic emission source location and velocity measurement. Int J Rock Mech Min Sci 32(8):741-750. doi:10.1016/0148-9062(95)00015-9

Meng Q, Zhang M, Han L, Pu H, Nie T (2016) Effects of acoustic emission and energy evolution of rock specimens under the uniaxial cyclic loading and unloading compression. Rock Mech Rock Eng 49(10):3873-3886. doi:10.1007/s00603-016-1077-y

Michalske T, Freiman S (1982) A molecular interpretation of stress corrosion in silica. Nature 295:511-512

Michalske T, Freiman S (1983) A molecular mechanism for stress corrosion in vitreous silica. J Am Ceram Soc 66(4):284-288

Miner M (1945) Cumulative damage in fatigue. J Appl Mech 12(3):159-164

Mitchell T, Faulkner D (2008) Experimental measurements of permeability evolution during triaxial compression of initially intact crystalline rocks and implications for fluid flow in fault zones. J Geophys Res Solid Earth 113(11):1-16. doi:10.1029/200 8JB005588

Momeni A, Karakus M, Khanlari GR, Heidari M (2015) Effects of cyclic loading on the mechanical properties of a granite. Int $\mathrm{J}$ Rock Mech Min Sci 77:89-96. doi:10.1016/j.ijrmms.2015.03.029

Morales Demarco M, Jahns E, Rüdrich J, Oyhantcabal P, Siegesmund S (2007) The impact of partial water saturation on rock strength: an experimental study on sandstone. Zeitschrift der Deutschen Gesellschaft für Geowissenschaften 158(4):869-882. doi:10.1127/1860-1804/2007/0158-0869

Munoz H, Taheri A (2017) Local damage and progressive localisation in porous sandstone during cyclic loading. Rock Mech Rock Eng. doi:10.1007/s00603-017-1298-8

Nara Y, Kaneko K (2006) Sub-critical crack growth in anisotropic rock. Int J Rock Mech Min Sci 43(3):437-453. doi:10.1016/j. ijrmms.2005.07.008

Nara Y, Morimoto K, Hiroyoshi N, Yoneda T, Kaneko K, Benson P (2012) Influence of relative humidity on fracture toughness of rock: implications for subcritical crack growth. Int J Solids Struct 49(18):2471-2481. doi:10.1016/j.ijsolstr.2012.05.009

Nejati H, Ghazvinian A (2014) Brittleness effect on rock fatigue damage evolution. Rock Mech Rock Eng 47(5):1839-1848. doi:10.1007/s00603-013-0486-4

Ni XH (2014) Failure characteristic of granite under cyclic loading with different frequencies. Appl Mech Mater 638:1967-1970

Pola A, Crosta G, Fusi N, Castellanza R (2014) General characterization of the mechanical behaviour of different volcanic rocks with respect to alteration. Eng Geol 169:1-13. doi:10.1016/j. enggeo.2013.11.011
Pouya A, Zhu C, Arson C (2016) Micro-macro approach of salt viscous fatigue under cyclic loading. Mech Mater 93:13-31. doi:10.1016/j.mechmat.2015.10.009

Prikryl R, Lokajicek T, Li C, Rudajev V (2003) Acoustic emission characteristics and failure of uniaxially stressed granitic rocks: the effect of rock fabric. Rock Mech Rock Eng 36:255-270. doi:10.1007/s00603-003-0051-7

Pujades E, Willems T, Bodeux S, Orban P, Dassargues A (2016) Underground pumped storage hydroelectricity using abandoned works (deep mines or open pits) and the impact on groundwater flow. Hydrogeol J. doi:10.1007/s10040-016-1413-z

Rajaram V (1981) Mechanical behavior of granite under cyclic compression. In: First international conference on recent advances in geotechnical earthquake engineering

Rao M, Ramana YV (1992) A study of progressive failure of rock under cyclic loading by ultrasonic and AE monitoring techniques. Rock Mech Rock Eng 25(4):237-251. doi:10.1007/BF01041806

Ritchie R (1999) Mechanisms of fatigue-crack propagation in ductile and brittle solids. Int J Fract 100:55-83. doi:10.102 3/A:1018655917051

Royer-Carfagni G, Salvatore W (2000) The characterization of marble by cyclic compression loading: experimental results. Mech Cohes Frict Mater 5(7):535-563. doi:10.1002/10991484(200010)5:7<535::AID-CFM102>3.0.CO;2-D

Schaefer L, Kendrick J, Oommen T, Lavallée Y, Chigna G, Costa A (2015) Geomechanical rock properties of a basaltic volcano. Front Earth Sci 3(June):1-15

Schijve J (2003) Fatigue of structures and materials. Fatigue Struct Mater 25:679-702. doi:10.1007/978-1-4020-6808-9

Scholz C, Kranz R (1974) Notes on dilatancy recovery. J Geophys Res 79(14):2132-2135

Scholz CH, Koczynski TA (1979) Dilatancy anisotropy and the response of rock to large cyclic loads. J Geophys Res 84(B10):5525. doi:10.1029/JB084iB10p05525

Shao J, Zhou H, Chau KT (2005) Coupling between anisotropic damage and permeability variation in brittle rocks. Int J Numer Anal Methods Geomech 29(12):1231-1247. doi:10.1002/nag.457

Shreiner LA, Pavlova NN (1958) Experimental data on the fatigue breakdown of rocks. Trudy Instituta Nefti Akademii Nauk SSSR, vol 2, Neftepromyslovoe Delo. Associated Technical Services, East Orange, NJ, pp 46-52

Singh S (1989) Fatigue and strain hardening behaviour of graywacke from the flagstaff formation, New South Wales. Eng Geol 26(2):171-179

Sondergeld C, Estey L (1981) Acoustic emission study of microfracturing during the cyclic loading of Westerly granite. J Geophys Res 86(B4):2915-2924. doi:10.1029/JB086iB04p02915

Song H, Zhang H, Fu D, Zhang Q (2016) Experimental analysis and characterization of damage evolution in rock under cyclic loading. Int J Rock Mech Min Sci 88:157-164. doi:10.1016/j. ijrmms.2016.07.015

Song R, Yue-ming B, Jing-Peng Z, De-yi J, Chun-he Y (2013) Experimental investigation of the fatigue properties of salt rock. Int $J$ Rock Mech Min Sci 64:68-72. doi:10.1016/j.ijrmms.2013.08.023

Sorgi C, De Gennaro V (2011) Water-rock interaction mechanisms and ageing processes in chalk. In: Chen D (ed) Advances in data, methods, models and their applications in geoscience. In Tech. doi: $10.5772 / 1133$

Steffen B (2012) Prospects for pumped-hydro storage in Germany. Energy Policy 45:420-429

Taheri A, Royle A, Yang Z, Zhao Y (2016) Study on variations of peak strength of a sandstone during cyclic loading. Geomech Geophys Geo-Energy Geo-Resour 2(1):1-10. doi:10.1007/ s40948-015-0017-8 
Tien Y, Lee D, Juang C (1990) Strain, pore pressure and fatigue characteristics of sandstone under various load conditions. Int J Rock Mech Min Sci Geomech Abstr 27(4):283-289

Tomkins B (1981) Subcritical crack growth: fatigue, creep and stress corrosion cracking. Philos Trans R Soc A Math Phys Eng Sci 299:31-44

Trippetta F, Collettini C, Meredith P, Vinciguerra S (2013) Tectonophysics evolution of the elastic moduli of seismogenic triassic evaporites subjected to cyclic stressing. Tectonophysics 592:6779. doi:10.1016/j.tecto.2013.02.011

Voznesenskii A, Krasilov M, Kutkin Y, Tavostin M, Osipov Y (2017) Features of interrelations between acoustic quality factor and strength of rock salt during fatigue cyclic loadings. Int J Fatigue 97:70-78. doi:10.1016/j.ijfatigue.2016.12.027

Voznesenskii A, Kutkin Y, Krasilov M, Komissarov A (2015) Predicting fatigue strength of rocks by its interrelation with the acoustic quality factor. Int J Fatigue 77(March):194-198. doi:10.1016/j. ijfatigue.2015.02.012

Voznesenskii A, Kutkin Y, Krasilov M, Komissarov A (2016) The influence of the stress state type and scale factor on the relationship between the acoustic quality factor and the residual strength of gypsum rocks in fatigue tests. Int J Fatigue 84:53-58. doi:10.1016/j.ijfatigue.2015.11.016

Wang H, Xu W, Cai M, Xiang Z, Kong Q (2017) Gas permeability and porosity evolution of a porous sandstone under repeated loading and unloading conditions. Rock Mech Rock Eng 50:2071-2083. doi:10.1007/s00603-017-1215-1

Wang W, Wang M, Liu X (2016) Study on mechanical features of Brazilian splitting fatigue tests of salt rock. Adv Civ Eng 2016:5436240. doi:10.1155/2016/5436240

Wang Z, Li S, Qiao L, Zhang Q (2015) Finite element analysis of the hydro-mechanical behavior of an underground crude oil storage facility in granite subject to cyclic loading during operation. Int $\mathbf{J}$ Rock Mech Min Sci 73:70-81. doi:10.1016/j.jirmms.2014.09.018

Wang Z, Li S, Qiao L, Zhao J (2013) Fatigue behavior of granite subjected to cyclic loading under triaxial compression condition. Rock Mech Rock Eng 46(6):1603-1615. doi:10.1007/ s00603-013-0387-6

Widhalm C, Tschegg E, Eppensteiner W (1996) Anisotropic thermal expansion causes deformation of marble claddings. J Perform Constr Facil 10(February):5-10

Wiederhorn S (1967) Influence of water vapor on crack propagation in soda-lime glass. J Am Ceram Soc 50(8):407-414

Xiao J, Ding D, Jiang F, Xu G (2010a) Fatigue damage variable and evolution of rock subjected to cyclic loading. Int J Rock Mech Min Sci 47(3):461-468. doi:10.1016/j.ijrmms.2009.11.003

Xiao J, Ding D, Xu G, Jiang F (2009) Inverted S-shaped model for nonlinear fatigue damage of rock. Int J Rock Mech Min Sci 46(3):643-648. doi:10.1016/j.ijrmms.2008.11.002
Xiao J, Feng X, Ding D, Jiang F (2010b) Investigation and modeling on fatigue damage evolution of rock as a function of logarithmic cycle. Int J Numer Anal Meth Geomech 35:1127-1140. doi:10.1002/nag

Yamashita S, Sugimoto F, Imai T, Namsrai D, Yamauchi M, Kamoshida $\mathrm{N}$ (1999) The relationship between the failure process of the creep or fatigue test and of the conventional compression test on rock. In: 9th ISRM congress, international society for rock mechanics

Yang S, Tian W, Ranjith P (2017) Experimental investigation on deformation failure characteristics of crystalline marble under triaxial cyclic loading. Rock Mech Rock Eng. doi:10.1007/ s00603-017-1262-7

Yang S-Q, Ranjith P, Huang Y-H, Yin P-F, Jing H-W, Gui Y-L, Yu Q-L (2015) Sandstone under triaxial cyclic loading. Geophys J Int 201:662-682. doi:10.1093/gji/ggv023

Zang A, Yoon J, Stephansson O, Heidbach O (2013) Fatigue hydraulic fracturing by cyclic reservoir treatment enhances permeability and reduces induced seismicity. Geophys J Int 195(August):1282-1287. doi:10.1093/gji/ggt301

Zhang P, Xu J, Li N (2008) Fatigue properties analysis of cracked rock based on fracture evolution process. J Cent South Univ 15:95-99. doi:10.1007/s1177100800196

Zhang S, Lai Y, Zhang X, Pu Y, Yu W (2004) Study on the damage propagation of surrounding rock from a cold-region tunnel under freeze-thaw cycle condition. Tunn Undergr Space Technol 19(3):295-302. doi:10.1016/j.tust.2003.11.011

Zhang ZX, Kou SQ, Jiang LG, Lindqvist P-A (2000) Effects of loading rate on rock fracture characteristics and energy partitioning. Int J Rock Mech Min Sci 37:745-762

Zhao J (2000) Applicability of Mohr-Coulomb and Hoek-Brown strength criteria to the dynamic strength of brittle rock. Int J Rock Mech Min Sci 37(7):1115-1121. doi:10.1016/ S1365-1609(00)00049-6

Zhenyu T, Haihong M (1990) An experimental study and analysis of the behaviour of rock under cyclic loading. Int J Rock Mech Min Sci Geomech Abstr 27(1):51-56

Zhu Q, Kondo D, Shao J, Pensee V (2008) Micromechanical modelling of anisotropic damage in brittle rocks and application. Int J Rock Mech Min Sci 45(4):467-477. doi:10.1016/j.jirmms.2007.07.014

Zhu W, Tang C (2006) Numerical simulation of Brazilian disk rock failure under static and dynamic loading. Int J Rock Mech Min Sci 43(2):236-252. doi:10.1016/j.ijrmms.2005.06.008

Zoback M, Byerlee J (1975) The effect of cyclic differential stress on dilatancy in westerly reduced repeated plied the is sub- on dilatancy in westerly granite. J Geophys Res 80(11):1526-1530 